\title{
Golgi-Dependent Copper Homeostasis Sustains Synaptic Development and Mitochondrial Content
}

\author{
${ }^{\circledR}$ Cortnie Hartwig, ${ }^{1}$ Gretchen Macías Méndez, ${ }^{2}$ Shatabdi Bhattacharjee, ${ }^{3}$ Alysia D. Vrailas-Mortimer, ${ }^{4}$

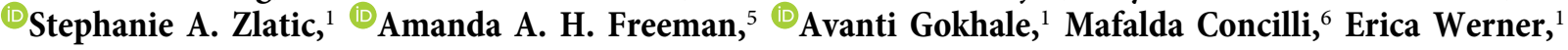 \\ Christie Sapp Savas, ${ }^{1}$ Samantha Rudin-Rush, ${ }^{1}$ Laura Palmer, ${ }^{1}$ Nicole Shearing, ${ }^{1}$ Lindsey Margewich, ${ }^{4}$ \\ Jacob McArthy, ${ }^{4}$ Savanah Taylor, ${ }^{4}$ Blaine Roberts, ${ }^{7}$ Vladimir Lupashin, ${ }^{8}$ Roman S. Polishchuk, ${ }^{6}$ \\ ${ }^{-}$Daniel N. Cox, ${ }^{3}$ Ramon A. Jorquera, ${ }^{2,9}$ and ${ }^{\circ}$ Victor Faundez ${ }^{1}$ \\ ${ }^{1}$ Departments of Cell Biology, Emory University, Atlanta, Georgia 30322, ${ }^{2}$ Neuroscience Department, Universidad Central del Caribe, Bayamon, Puerto \\ Rico 00956, ${ }^{3}$ Neuroscience Institute, Center for Behavioral Neuroscience, Georgia State University, Atlanta, Georgia 30302, ${ }^{4}$ School of Biological Sciences, \\ IL State University, Normal, Illinois 617901, ${ }^{5}$ The Center for the Study of Human Health, Emory University, Atlanta, Georgia 30322, ${ }^{6}$ Telethon Institute of \\ Genetics and Medicine (TIGEM), Pozzuoli 80078, Italy, ${ }^{7}$ Departments of Biochemistry, Emory University, Atlanta, Georgia 30322, ${ }^{8}$ Department of \\ Physiology and Biophysics, University of Arkansas for Medical Sciences, Little Rock, Arkansas 72205, and ${ }^{9}$ Institute of Biomedical Sciences, Faculty of \\ Medicine and Faculty of Life Sciences, Universidad Andres Bello, Santiago 8370186, Chile
}

Rare genetic diseases preponderantly affect the nervous system causing neurodegeneration to neurodevelopmental disorders. This is the case for both Menkes and Wilson disease, arising from mutations in ATP7A and ATP7B, respectively. The ATP7A and ATP7B proteins localize to the Golgi and regulate copper homeostasis. We demonstrate genetic and biochemical interactions between ATP7 paralogs with the conserved oligomeric Golgi (COG) complex, a Golgi apparatus vesicular tether. Disruption of Drosophila copper homeostasis by ATP7 tissue-specific transgenic expression caused alterations in epidermis, aminergic, sensory, and motor neurons. Prominent among neuronal phenotypes was a decreased mitochondrial content at synapses, a phenotype that paralleled with alterations of synaptic morphology, transmission, and plasticity. These neuronal and synaptic phenotypes caused by transgenic expression of ATP7 were rescued by downregulation of COG complex subunits. We conclude that the integrity of Golgi-dependent copper homeostasis mechanisms, requiring ATP7 and COG, are necessary to maintain mitochondria functional integrity and localization to synapses.

Key words: ATP7A; copper; Golgi; Menkes; mitochondria; Wilson

Significance Statement

Menkes and Wilson disease affect copper homeostasis and characteristically afflict the nervous system. However, their molecular neuropathology mechanisms remain mostly unexplored. We demonstrate that copper homeostasis in neurons is maintained by two factors that localize to the Golgi apparatus, ATP7 and the conserved oligomeric Golgi (COG) complex. Disruption of these mechanisms affect mitochondrial function and localization to synapses as well as neurotransmission and synaptic plasticity. These findings suggest communication between the Golgi apparatus and mitochondria through homeostatically controlled cellular copper levels and copper-dependent enzymatic activities in both organelles.

\section{Introduction}

Rare diseases include genetic maladies that disproportionately affect the nervous system with phenotypes ranging from neurodegeneration to behavioral impairments (Sanders et al., 2019;

Received May 22, 2020; revised Oct. 2, 2020; accepted Nov. 9, 2020

Author contributions: G.M.M., S.B., A.D.V.-M., S.A.Z., A.A.H.F., A.G., M.C., E.W., B.R., R.S.P., D.N.C., R.A.J., and V.F. designed research; C.H., G.M.M., S.B., A.D.V.-M., S.A.Z., A.A.H.F., A.G., M.C., E.W., C.S.S., S.R.-R., L.P., N.S., L.M., J.M., S.T., B.R., and R.A.J. performed research; V.L. and D.N.C. contributed unpublished reagents/analytic tools; C.H., S.B., A.D.V.-M., S.A.Z., A.A.H.F., E.W., B.R., R.S.P., D.N.C., R.A.J., and V.F. analyzed data; V.F. wrote the paper.

C.H., G.M.M., S.B., and A.D.V.-M. contributed equally to this work.

This work was supported by National Institutes of Health (NIH) Grants 1RF1AG060285 (to V.F.), R01NS108778 and R01NS108778-01S1 (to R.A.J.), R15AR070505 (to A.D.V.-M.), Telethon TIGEM-CBDM9
Lee et al., 2020). The vast collection of mutated human genes and neurologic symptomatology offers a wide field for the discovery of novel cellular mechanisms necessary for neuronal function. Here, we focus on rare neurologic diseases affecting

(to R.S.P.), R01NS086082 (to D.N.C.), R01GM083144 (to V.L.), and 5K12GM000680-19 (to C.H.). Stocks obtained from the Bloomington Drosophila Stock Center (NIH Grant P400D018537) were used in this study. The authors declare no competing financial interests. Acknowledgements: We thank the Faundez lab members for their comments.

Correspondence should be addressed to Ramon A. Jorquera at ramon.jorquera@unab.cl or Victor Faundez at vfaunde@emory.edu.

https://doi.org/10.1523/JNEUROSCI.1284-20.2020

Copyright $\odot 2021$ the authors 
ATP7A, ATP7B, and the conserved oligomeric Golgi (COG) complex subunit genes, whose products localize to the Golgi complex at steady state (Kaler, 2011; Polishchuk and Lutsenko, 2013; Climer et al., 2015). We report that these ATP7 paralogs and the COG complex converge to maintain copper homeostasis and, unexpectedly, mitochondrial distribution in neurons.

Mutations in the ATP7A cause Menkes disease, a systemic copper-depletion affliction caused by intestinal copper malabsorption. Menkes is characterized by childhood systemic and neurologic phenotypes. Menkes' brain phenotypes result from this systemic copper depletion and span from intellectual disability to widespread gray matter neurodegeneration. (Menkes, 1988, 1999; Kaler, 2011; Zlatic et al., 2015; Hartwig et al., 2019; Guthrie et al., 2020). These Menkes disease phenotypes are caused in part by defects in the activity of copper-dependent enzymes that either traverse the Golgi complex or localize to mitochondria (Lutsenko et al., 2007; Zlatic et al., 2015). In contrast, with the systemic depletion of copper observed in Menkes patients, cell-autonomous ATP7A gene defects cause a cellular overload of copper because of impaired copper efflux from cells (Camakaris et al., 1980; Morgan et al., 2019). This ATP7A cell-autonomous copper phenotype can be recapitulated systemically in Wilson disease. Wilson disease is caused by mutations in the ATP7A paralogue, ATP7B, a copper transporter gene expressed preferentially in the liver. Wilson disease leads to organismal copper overload because of defective copper excretion by the liver. This systemic copper overload causes liver damage, psychiatric symptoms, and lenticular neurodegeneration at late stages of disease (Lutsenko et al., 2007; Kaler, 2011).

ATP7A and ATP7B are P-type ATPases residing in the Golgi complex at steady state where they contribute to cellular copper homeostasis. These ATPases sequester copper into the Golgi lumen away from the cytoplasm by a mechanism that requires ATP hydrolysis to drive copper transport. Furthermore, after a copper challenge, these ATPases are translocated to the plasma membrane where they pump copper outside of the cell (Petris et al., 1996; Kaler, 2011; Polishchuk and Lutsenko, 2013; Polishchuk et al., 2014). In turn, extracellular copper is taken up by the activity of a plasma membrane copper transporter CTR1 (Kuo et al., 2001; Lutsenko et al., 2007; Kaler, 2011). The expression of ATP7A and CTR1 is controlled by the activity of the COG complex, which tethers vesicles to the Golgi complex (Comstra et al., 2017). The COG complex is an octamer localized to the Golgi apparatus and required for incoming vesicle fusion with the Golgi. Elimination of any one of the eight COG subunits leads to Golgi fragmentation because of destabilization and degradation of the whole octamer (Ungar et al., 2002; Zolov and Lupashin, 2005; Climer et al., 2015; Bailey Blackburn et al., 2016). Human mutations in seven of the eight COG subunits cause a group of diseases collectively known as congenital disorder of glycosylation Type II (Wu et al., 2004; Kranz et al., 2007; Foulquier, 2009; Climer et al., 2015). These rare disorders are characterized, in part, by neurodevelopmental pathology and behavioral phenotypes which are loosely similar to neurologic phenotypes in Menkes disease. However, whether congenital disorder of glycosylation Type II neurologic phenotypes may be linked to copper metabolism remains unanswered (Climer et al., 2018).

The convergence of neurologic, neurodevelopmental, and psychiatric phenotypes in these three diseases with proteins localizing to the Golgi complex, point to fundamental, neuronal mechanisms necessary to maintain cellular copper homeostasis. These phenotypes raise the question: how are the activities of copper transporters and the COG complex coordinated to maintain copper homeostasis in cells, tissues, and organisms? Here, we demonstrate that ATP7 paralogues and the COG complex, both Golgi localized machineries, control synapse development, neurotransmission, and the subcellular localization of mitochondria at synapses.

\section{Material and Methods}

Drosophila strains

The following strains where obtained from the Bloomington Drosophila Stock Center, Bloomington, IL: $\mathrm{w}^{1118}$ (\#5905), pnrGAL4 (\#3039), Ddc-GAL4 (\#7009), elav ${ }^{\mathrm{C} 155}$-GAL4 (\#458), UAS-COG1 RNAi (\#38943), UAS-COG5 RNAi (\#56882), UASCOG8 RNAi (\#55192), Cog1 $1^{\mathrm{e} 02840}$ (\#18089), Mito-GFP (\#25748). UAS-ATP7-wt (OE) and UAS-ATP7-FLAG (OE1) were gifts of Richard Burke, Monash University, Australia. The UAS-ATP7 RNAi (\#108159) stock was obtained from the Vienna Drosophila Resource Center. GAL4 ${ }^{477}$, UAS-mCD8::GFP/CyO, tubP-GAL80; GAL4$^{\text {ppk.1.9 }}$, UAS-mCD8::GFP (CIV-GAL4 driver), GAL4 ${ }^{477}$, UASmito-HA-GFP.AP/CyO;ppk::tdTomato, and OregonR (wild-type) were used for dendritic analysis. UAS-mito-HA-GFP.AP line was obtained from Bloomington (\#8442).

\section{Antibodies and beads}

Antibodies used in Drosophila stainings were anti-HRP-FITC (MP Biomedicals, 0855977, RRID:AB_2334736), phalloidinrhodamine (Abcam, ab235138), phalloidin-Alexa Fluor 633 (Invitrogen, A22284), anti-Cy3 (Santa Cruz Biotechnology, 166894), the primary antibody rabbit anti-GFP (Sysy 132002, RRID:AB_887725), and the secondary antibody Alexa Fluor 488 goat anti-rabbit (Invitrogen).

The following antibodies were used: rabbit anti COG7 from V. Lupashin's laboratory, rabbit anti-COG5 (HPA020300, Sigma, RRID:AB_2081406), mouse monoclonal anti-GOLGIN 97 CDF4 (A-21270, Thermo Fisher Scientific, RRID:AB_ 221447), mouse anti-Lamp1 (DSHB H4A3-c, Developmental Studies Hybridoma Bank, RRID:AB_528126), rabbit anti-ATP7B (AB124973, Abcam, RRID:AB_10975785), mouse anti-GAPDH (0411; sc-47 724, Santa Cruz, RRID:AB_627678), mouse antimyc (c-myc (9E10), sc-40, Santa Cruz, RRID:AB_627268), mouse anti-FLAG M2 (F3165, Sigma, RRID:AB_259529), rabbit anti-COX11 (11 498-1-AP, Proteintech, RRID:AB_10598173), rabbit anti-COX17 (HPA048158, Sigma, RRID:AB_2680292), rabbit anti-MPC1 (HPA045119, Sigma, RRID:AB_10960421), mouse anti-MFN1 (ab126575, Abcam, RRID:AB_11141234), rabbit antiSeladin/DHCR24 (10 471-1-AP, Proteintech, RRID:AB_2091446), rabbit anti-HSP60 (12 165, Cell Signaling, RRID:AB_2636980), rabbit anti-SDHA (11998, Cell Signaling, RRID:AB_2750900), and mouse monoclonal F-10 anti-Tomm20 (sc-17 764, Santa Cruz, RRID:AB_628381). The following beads were used in immunoprecipitations: protein A-Sepharose 4 B Fast Flow from Staphylococcus aureus (P9424, Sigma), Protein G Sepharose four Fast Flow (17-0618-01, GE Healthcare), Dynal magnetic beads (110.31, Invitrogen).

\section{Drosophila immunofluorescence microscopy}

For experiments where larval neuromuscular junctions were analyzed, Drosophila stocks were reared in polystyrene vials on standard fly food ( $900 \mathrm{ml}$ milli-Q water, $48 \mathrm{~g}$ active dry yeast, $120 \mathrm{~g}$ cornmeal, $9 \mathrm{~g}$ agar, $120 \mathrm{~g}$ molasses, $2.4 \mathrm{~g}$ tegosept, and $9 \mathrm{ml}$ propionic acid). Animals were housed in a humidified, $25^{\circ} \mathrm{C}$ incubator (Jeio Tech Co, Inc, IB-15G) with a 12/12 h light/dark cycle. 
Larval NMJ dissections, immunohistochemistry, and confocal microscopy were performed as described previously (Gokhale et al., 2015b, 2016; Mullin et al., 2015). Wandering late third-instar female larvae were dissected with a dorsal incision in a $10 \mathrm{~mm}$ cell culture dish in normal HL3 composed of $70 \mathrm{~mm} \mathrm{NaCl}, 5 \mathrm{~mm}$ $\mathrm{KCl}, 21.5 \mathrm{~mm} \mathrm{MgCl}_{2}, 10 \mathrm{~mm} \mathrm{NaHCO}$, $5 \mathrm{~mm}$ trehalose, $115 \mathrm{~mm}$ sucrose, and $5 \mathrm{~mm} \mathrm{BES}, \mathrm{pH} 7.2-7.3$. Larvae were fixed in $4 \%$ paraformaldehyde for $1 \mathrm{~h}$ at room temperature (RT) and stained with anti-HRP-FITC (1:500) and anti-phalloidin-rhodamine (1:1000; data not shown, used for muscle orientation) in PBS supplemented with $0.1 \%$ Triton X-100 (PBS-T) overnight at $4^{\circ} \mathrm{C}$. All steps were followed by three 10 min rinses in PBS-T and a final rinse in PBS. The larval preparation was affixed to a poly-Llysine coated glass side with a drop of Vectashield (Vector Labs H-1000-10) and coverslipped. The coverslip was adhered to the slide with a layer of nail polish in preparation for inverted microscopy. Samples were stored at $4^{\circ} \mathrm{C}$ until imaged. An inverted Olympus FV1000 microscope was used for confocal imaging of synapses on muscle 6/7 in the A3 segment. Maximum intensity projections were converted to jpegs. Total NMJ length and bouton perimeter measurements were calculated in FIJI (Schindelin et al., 2012). The FIJI Cell Counter plugin was used to quantify bouton number (Rai et al., 2018). All files were blind for quantification.

For body wall mosaics, larvae were dissected, fixed, and stained as described above; however, a lateral incision was made to preserve one set of the somatic musculature. The dissection was incubated in the primary antibodies anti-phalloidin-633 (1:500), anti-HRP-Cy3 (1:1000), and rabbit anti-GFP (1:1000) overnight at $4^{\circ} \mathrm{C}$ and incubated with Alexa Fluor 488 goat antirabbit (1:1000) with additional anti-phalloidin-633 (1:500), and anti-HRP-Cy3 (1:1000) for $2 \mathrm{~h}$ at RT the following day before placement on a slide. Mosaics were imaged using the Multi Area Time Lapse Controller of the Olympus FV1000 confocal microscope. Image stitching was completed, and mosaics converted to jpegs with the Multi Area Time Lapse Viewer of Olympus Fluoview software.

For live confocal imaging, GAL4 ${ }^{477}$, UAS-mCD8::GFP; GAL4 ${ }^{\text {pkk.1.9 }}$, UAS-mCD8::GFP virgin flies were crossed to males from individual transgenic fly lines, or outcrossed to OregonR males which served as control. Fluorescent neurons from wandering third-instar larvae were imaged on a Zeiss LSM780 confocal microscope as previously described (Das et al., 2017). Briefly, individual animals were placed in a microscopic slide and immersed in 1:5 (v/v) diethyl ether to halocarbon oil and covered with a $22 \times 50$-mm coverslip. Images were collected as $z$-stacks using the $20 \times$ dry objective at a step-size of $2 \mu \mathrm{m}$. Maximum intensity projections of the images acquired were exported using the Zen blue software. The images were then manually curated using the Flyboys software to remove non-specific background noise such as denticle belts. The ImageJ software was used to skeletonize and process these images as previously described (Iyer et al., 2013a,b), and custom Python algorithms used to compile quantitative data such as total dendritic length and number of branches. For Strahler order analysis, images were reconstructed using NeuronStudio and the branch order extracted using the centripetal branch order function (Rodriguez et al., 2008).

For mitochondrial analysis, virgin female flies from GAL4 ${ }^{477}$, UAS-mito-HA.GFP.AP/Cyo;ppk-tdTomato were outcrossed to either males from OregonR (control) or individual transgenic fly lines. Images were acquired as described above and maximum intensity projections of the $\mathrm{z}$ stacks were exported using Zen Blue software. Using Adobe Photoshop, images were cropped to a fixed size $(6.6 \times 4.5$ inches $)$ in the same quadrant of the neurons and the mitochondria manually counted along the dendrites in these quadrants. The cropped images were processed as described above to obtain the total dendritic length which was then used to analyze the number of organelles per 1000 pixels dendritic length. For branch point analysis, mitochondria localized at branch points were manually counted and normalized to the total number of branch points.

\section{Drosophila viability}

For experiments measuring animal viability, flies were reared on standard Molasses Food (Genesee Scientific) at $25^{\circ} \mathrm{C}$ in $12 / 12 \mathrm{~h}$ light/dark cycle. The total number of balanced (control) and unbalanced (experimental) male and female adult offspring from each cross was counted every 1-2 d for $9 \mathrm{~d}$ with at least 200 offspring scored. Viability was observed with at least three replicate vials per experiment. Four to five flies per genotype per sex, where available, were imaged at $4 \times$ magnification (Gokhale et al., 2015a; Zlatic et al., 2018).

\section{Drosophila copper toxicity}

Male and female flies were collected at eclosion and aged 4-7 d. Flies were then starved for $3 \mathrm{~h}$ before being placed in empty vials that contained a filter disk soaked with $200 \mu \mathrm{l}$ of $100 \mathrm{~mm} \mathrm{CuSO}_{4}$. Approximately 10 flies per sex per genotype were analyzed with a minimum of six replicates. Flies were maintained at $25^{\circ} \mathrm{C}$ in a $12 / 12 \mathrm{~h}$ light/dark cycle and the number of dead flies was assessed daily (Gokhale et al., 2015a; Zlatic et al., 2018).

\section{Drosophila synaptic physiology}

Drosophila were raised in supplemented fly food (German Formulation, Genesee Scientific), at $2^{\circ} \mathrm{C}$ temperature and $80 \%$ of humidity. Recordings were performed in Modified HL3 solution (10 mм $\mathrm{NaHCO}_{3}, 5 \mathrm{~mm} \mathrm{KCl,} 4 \mathrm{~mm} \mathrm{MgCl,} 5$ mм HEPES, $70 \mathrm{~mm}$ $\mathrm{NaCl}, 5 \mathrm{~mm}$ trehalose, and $115 \mathrm{~mm}$ sucrose; $\mathrm{pH}$ 7.2). The final $\mathrm{Ca}^{2+}$ concentration was set to the desired level indicated in the text. Postsynaptic currents from specific genotypes were recorded at segment A3 of ventral longitudinal muscle 6 as indicated in third-instar larvae using two-electrode voltage clamp with a $-80-\mathrm{mV}$ holding potential as was previously described (Acharya et al., 2006; Jorquera et al., 2012; Stevens et al., 2012; Astorga et al., 2016). The motor nerves innervating the specified muscles were severed and placed into a suction electrode, so an action potential could be evoked by electrical stimulation at the indicated frequencies using a programmable stimulator (Master8, AMPI). Each stimulus was adjusted to 6-V intensity for $0.1-\mathrm{ms}$ duration, allowing to recruit both motor neurons and preventing electrotonic induced hyperexcitability.

Data Acquisition and analysis was performed using the National Instrument DAQ system controlled by WinEDR software (University of Strathclyde) on a desktop computer. Electrical recordings were analyzed using Clampfit 10 software (Molecular Devices) or IgorPro 4.0 software (WaveMetrics). Graphs and statistics were generated using OriginPro 9.0 software (OriginLab Corp), and Microsoft Excel routines.

To quantify the post-tetanic plasticity in the different genotypes, we adjusted the normalized post-tetanic responses with a previously described model that adds depression in the function as $\mathrm{P} \cdot \mathrm{e}^{\wedge}(-\mathrm{X} / \tau)+1-\mathrm{D}$, were $\mathrm{P}$ is the post-tetanic potentiation (PTP) and D the post-tetanic depression (PTD), which decays between two states with a time constant tau. To solve this function, we used numerical solutions by repetitive iteration with 
solver routines minimizing the summation of the squares of the differences between the data and the model. To help the simulation, we incorporated values of potentiation and depression obtained during the tetanic stimulation. Numerical analysis of normalized post-tetanic enhancement in control and mutant animals generates values for potentiation, depression, and the time constant.

\section{Quantitation of total copper}

The measurement of total copper was conducted as previously described (McAllum et al., 2020). Briefly, quantitation of copper metal in larva were determined with a Thermo iCAP-TQ series inductively coupled plasma mass spectrometer (ICP-MS). The instrument was operated in kinetic energy discrimination (KED) mode using $\mathrm{He}$ as a collision gas to remove polyatomic interferences. Quantitation of copper (as $\mathrm{m} / \mathrm{z}$ 63) was determined with nine-point external calibration curve (Accustandard, AGMECAL2A-ASL-5) generated using 1000 and $100 \mu \mathrm{g} \mathrm{l}^{-1}$ stock solutions of standard with online dilutions conducted by the prepFast M5 system (Elemental Scientific) and ranged from

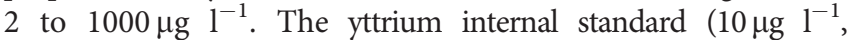
Accustandard, AG-INT2-ASL-5) was mixed with the sample online with the prepFast system. The wash, sample dilution, and sample carrier solutions were $2 \%$ nitric acid in $18.2-\Omega$ water. The wet weight of each larva was determined, and each larva were digested at $95^{\circ} \mathrm{C}$ for $10 \mathrm{~min}$ in $20 \mu \mathrm{l}$ of concentrated (70\%) nitric acid (metal basis grade-225711, Aldrich) followed by overnight at RT. The samples were then diluted $30 \times$ with $2 \%$ nitric acid to a final volume of $600 \mu \mathrm{l}$. This solution was transferred to a polypropylene 96-deepwell plate (Greiner Bio-One $\mathrm{GmbH}, 780201$ ), and samples were measured directly from the 96-well plate with M5 prepFast autosampler using $250-\mu \mathrm{l}$ sample loops.

\section{Cell culture}

SH-SY5Y (ATCC, RRID:CVCL_0019) and HEK293T (RRID: CVCL_0063) cells were cultured in DMEM supplemented with $10 \%$ fetal bovine serum (FBS) and $100 \mu \mathrm{g} / \mathrm{ml}$ penicillin and streptomycin at $37^{\circ} \mathrm{C}$ in $10 \% \mathrm{CO}_{2}$. HEK293T cells deficient for COG subunits were generated as described (Blackburn and Lupashin, 2016; Willett et al., 2016). HepG2 cells (RRID:CVCL_ 0027) were grown in DMEM supplemented with $10 \%$ FBS (decomplemented at $56^{\circ} \mathrm{C}$ for $30 \mathrm{~min}$ ), $2 \mathrm{~mm}$ L-glutamine, $100 \mu \mathrm{g} / \mathrm{ml}$ penicillin, and streptomycin at $37^{\circ} \mathrm{C}$ in $10 \% \mathrm{CO}_{2}$. HepG2 copper incubations were performed by adding 200 $\mu \mathrm{M} \mathrm{CuSO}{ }_{4}$ or $400 \mu \mathrm{M} \mathrm{BCS}$ diluted in DMEM at $37^{\circ} \mathrm{C}$ in $\mathrm{a} \mathrm{CO}_{2}$ incubator for $2 \mathrm{~h}$.

SH-SY5Y (ATCC, RRID:CVCL_0019) were genome edited using gRNA and Cas9 preassembled complexes by Synthego with a knock-out efficiency of $80 \%$. The gRNAs used was ACAGACUCCAAAGACCCUAC which targeted transcript ENST 00000341514 exon 3. Wild-type and mutant cells were cloned by clonal dilution and clones mutagenesis was confirmed by Sanger sequencing.

\section{Immunoprecipitation of ATP7 paralogues}

SH-SY5Y cells were grown to $80-90 \%$ confluency in $10-\mathrm{cm}$ tissue culture dishes. On the day of the experiment, cells were washed twice in ice cold PBS followed by lysis in a buffer containing 150 mM NaCl, $10 \mathrm{~mm}$ HEPES, $1 \mathrm{~mm}$ EGTA, and $0.1 \mathrm{~mm} \mathrm{MgCl}_{2}$, with $0.5 \%$ Triton X-100 and Complete Protease Inhibitor (Roche 11245200), $\mathrm{pH} 7.4$. The lysate was sonicated and incubated on ice for $30 \mathrm{~min}$ followed by a clarifying spin at $16,100 \times g$ for $10 \mathrm{~min}$. The soluble supernatant was obtained and $500 \mu \mathrm{g}$ of the protein lysate was added to $30 \mu \mathrm{l}$ Dynal magnetic beads coated with $5 \mu \mathrm{l}$ ATP7A antibody (75-142, NeuroMab, RRID: AB 10672736) and incubated for $2 \mathrm{~h}$ at $4^{\circ} \mathrm{C}$ in an end-to-end rotor. As negative controls, immunoprecipitations were done in the presence of a custom made antigenic ATP7A peptide (VSLEEKNATIIYDPKLQTPK, Biosynthesis) prepared in 10 mM MOPS and used at $22 \mu \mathrm{m}$ (Comstra et al., 2017). Additionally as a non-specific antibody control, we used equivalent amounts of the monoclonal antibody against FLAG (F3165, Sigma, RRID:: AB_259529). After the incubation period, magnetic beads were washed six times in a buffer containing $150 \mathrm{~mm} \mathrm{NaCl}, 10 \mathrm{~mm}$ HEPES, $1 \mathrm{~mm}$ EGTA, and $0.1 \mathrm{~mm} \mathrm{MgCl}_{2}, \mathrm{pH} 7.4$ with $0.1 \%$ Triton X-100. Proteins were eluted from the beads with Laemli sample buffer. Samples were resolved by SDS-PAGE and contents analyzed by immunoblot.

For immunoprecipitations using HepG2 cells, cells were solubilized at $4^{\circ} \mathrm{C}$ for $10 \mathrm{~min}$ at RT in a lysis buffer containing $0.5 \%$ Triton X-100, $20 \mathrm{~mm}$ Tris/HCl (pH 7.4), $150 \mathrm{~mm} \mathrm{NaCl}, 1 \mathrm{~mm}$ EDTA (pH 8), 0.5\% NP-40, and 10\% glycerol, supplemented with $1 \times$ protease inhibitor cocktail (Sigma). The mixture was placed into a Microfuge tube, kept on ice for $10 \mathrm{~min}$, and then centrifuged at $16,100 \times g$ for $15 \mathrm{~min}$ at $4^{\circ} \mathrm{C}$. Cell lysates were incubated with anti-ATP7B antibody overnight or with antiFLAG and anti-Myc antibodies as controls. Then protein A or G Sepharose beads were added to each specimen for $4 \mathrm{~h}$, and immune complexes were collected by centrifugation. The beads were then washed and immunoprecipitated proteins were eluted with sample buffer, separated by SDS-PAGE and analyzed by Western blotting.

\section{RNA interference}

Small interfering RNAs (siRNAs) targeting COG5 were purchased from Sigma-Aldrich. The following siRNA were used: CCAUUCAUAGUUGGCAGUU and GGACUUUGAAGGAU ACUA.

Scrambled siRNAs were used as a control. HepG2 cells were transfected with siRNAs using Dharmafect4 (Dharmacon T2004), according to manufacturer instructions.

\section{RNA preparation and $q R T-P C R$}

Control cells and COG5-silenced cells were lyzed and total RNA purified by QIAshredder (QIAGEN) and extracted with RNeasy Protect Mini kit (QIAGEN) using standard conditions. Total RNA $(1 \mu \mathrm{g})$ was reverse-transcribed by QuantiTect Reverse Transcription kit (QIAGEN) according to the manufacturer's instructions. qRT-PCR experiments were performed using Light Cycler 480 Syber Green MasterMix (Roche) for cDNA amplification and LightCycler 480 II (Roche) for signal detection. qRTPCR results were analyzed using the comparative Ct method normalized against housekeeping gene $\beta$-Actin. The following primers were used: $\beta$-ACTIN forward $\left(5^{\prime}\right.$-AAGAGCTACG AGCTGCCTGA-3'), $\beta$-ACTIN reverse (5'-GACTCCATGCC CAGGAAGG-3'), COG5 forward ( $5^{\prime}$-AGAGCCCGACTTGA AGTGGAAA- $\left.3^{\prime}\right)$, and COG 5 reverse ( $5^{\prime}$-ACCTGAAGAGCTG TTCCGACTT-3').

\section{Immunofluorescence}

For HEPG2 cells, control and COG5-silenced cells were fixed ( $10 \mathrm{~min}, 4 \%$ paraformaldehyde in $0.2 \mathrm{M}$ HEPES) directly or $2 \mathrm{~h}$ after incubation with $200 \mu \mathrm{M} \mathrm{CuSO}_{4}$. Fixed cells were then incubated with blocking/permeabilizing solution ( $0.5 \%$ bovine serum albumin, $0.1 \%$ saponin, $50 \mathrm{~mm} \mathrm{NH}_{4} \mathrm{Cl}$ in PBS) for 20-30 min. Primary and secondary antibodies were diluted in blocking/ 
permeabilizing solution and added to the cells for $1 \mathrm{~h}$ and 45 min, respectively. Samples were examined with a Zeiss LSM 700 confocal microscope equipped with a $63 \times 1.4 \mathrm{NA}$ oil objective.

For HEK293 cells, control and COG1 mutant cells were plated onto Matrigel coated coverslips and incubated at $37^{\circ} \mathrm{C}, 5 \%$ $\mathrm{CO}_{2}$ overnight in DMEM (Corning, 10-013-CV) supplemented with 10\% FBS (97068-085, VWR). Cells were washed twice in $37^{\circ} \mathrm{C}$ warmed PBS (21-040-CV, Corning) supplemented with 1 $\mathrm{mm} \mathrm{MgCl}_{2}$ and $100 \mu \mathrm{M} \mathrm{CaCl}$ and fixed at $37^{\circ} \mathrm{C}$ for $20 \mathrm{~min}$ in warmed, $4 \%$ paraformaldehyde (P6148, Sigma) in PBS/1 mM $\mathrm{MgCl}_{2} / 100 \mu \mathrm{M} \mathrm{CaCl}$. Fixed cells were blocked and permeablized for $30 \mathrm{~min}$ at RT in block solution containing, 2\% BSA (03116956001, Roche), 1\% fish gelatin (G7765, Sigma), 0.02\% saponin (S4521, Sigma), and 15\% horse serum (SH30074.03, HyClone) in PBS. Cells were incubated with primary antibody the mouse monoclonal anti-Tomm20 antibody diluted 1:200 in block solution at $37^{\circ} \mathrm{C}$ for $30 \mathrm{~min}$. Coverslips were washed three times in Block Solution and incubated with secondary antibody [Alexa Fluor 555 goat anti-mouse $\operatorname{IgG}(\mathrm{H}+\mathrm{L})$, A21422, Invitrogen, RRID:AB_2535844] diluted 1:1000 in block solution at $37^{\circ} \mathrm{C}$ for $30 \mathrm{~min}$. Coverslips were then washed twice in Blocking Solution, once in PBS/1 mM $\mathrm{MgCl}_{2} / 100 \mu \mathrm{M}$ $\mathrm{CaCl}_{2}$ and mounted on slides with Dapi Fluoromount-G (0100-20, Southern Biotech).

Coverslips were imaged on a Nikon Ti2-E inverted microscope $60 \times$ oil immersion Apo objective, NA 1.40 with a Galvano scanner. DAPI acquisition settings include excitation/emission wavelength of 405.0/450.0, laser scan confocal with PMT detector. Alexa Fluor 555 acquisition settings include excitation/emission wavelength or 561.0/595.0 Laser Scan Confocal with a $\mathrm{GaAsP}$ detector. Images were captured with a Nikon A1 LFOV camera. NIS-Elements C Imaging v5.20.01 and Imaris software were used for data collection, analysis, and $3 \mathrm{D}$ reconstruction.

\section{Extracellular flux analysis of tissue culture cells}

All oxygen consumption rates were measured on the Seahorse XFe96 Analyzer (Seahorse Bioscience) following manufacturer recommendations. XFe96 extracellular flux assay kit probes (Seahorse Bioscience 102601-100) were incubated with the included calibration solution overnight at $37^{\circ} \mathrm{C}$ under non- $\mathrm{CO}_{2-}$ injected conditions. Cells were trypsinized, counted (Bio-Rad TC20 automated Cell Counter), and seeded into XFe96 cell culture microplates (Seahorse Bioscience 101085-004) at 20,000 cells/well and incubated at $37^{\circ} \mathrm{C}$ with $10 \% \mathrm{CO}_{2}$ in complete culture media for $24 \mathrm{~h}$ before initialization of the stress test. The next day, wells were washed twice in Seahorse stress test media consisting of Seahorse XF base media (Seahorse Bioscience 102353-100), 2 mm L-glutamine (HyClone SH30034.01), $1 \mathrm{~mm}$ sodium pyruvate (Sigma S8636), and $10 \mathrm{~mm}$ D-glucose (Sigma G8769), pH7.4 before final volume added and then incubated at $37^{\circ} \mathrm{C}$ in non- $\mathrm{CO}_{2}$-injected conditions for $1 \mathrm{~h}$ before stress test. Seahorse injection ports were filled with 10 -fold concentrated solution of disulfiram (Sigma 86720), oligomycin A (Sigma 75351 ), carbonyl cyanide-4-(trifluoromethoxy)phenylhydrazone (FCCP; Sigma C2920), and rotenone (Sigma R8875)/antimycin A (Sigma A8674) for final testing conditions of disulfiram $(0.1 \mu \mathrm{M})$, oligomycin $(1.0 \mu \mathrm{M})$, FCCP $(0.125 \mu \mathrm{M})$, rotenone $(0.5 \mu \mathrm{M})$, and antimycin A $(0.5 \mu \mathrm{M})$. The flux analyzer protocol conditions consisted of three basal read cycles, 40 reads following disulfiram injection, and three reads following each injection of oligomycin A, FCCP, and rotenone plus antimycin $\mathrm{A}$. Each read cycle consisted of a 3-min mix cycle, followed by a 3-min read cycle where oxygen and $\mathrm{pH}$ levels were determined over time. The Seahorse Wave Software version 2.2.0.276 was used for data analysis of oxygen consumption rates. Experiments were repeated in quadruplicate and aliquots of each batch of stress test media were sent for inherent copper concentration analysis by ICP mass spectrometry performed by the Center for Applied Isotope Studies (CAIS) at the University of Georgia. Nonmitochondrial respiration was determined as the lowest oxygen consumption rate following injection of rotenone plus antimycin A. Basal respiration was calculated from the oxygen consumption rate just before oligomycin injection minus the non-mitochondrial respiration. Acute response was calculated from the difference in oxygen consumption rates just before disulfiram injection to just before oligomycin injection. Oligomycin A sensitivity was calculated as the difference in oxygen consumption rates just before oligomycin injection to the minimum oxygen consumption rate following oligomycin injection but before FCCP injection.

\section{Evolutionary rate covariation analysis}

We used the web engine https://csb.pitt.edu/erc_analysis/ (Clark et al., 2012, 2013; Findlay et al., 2014) using as inputs the CORUM annotated complexes database (Ruepp et al., 2010).

\section{Statistical analysis}

Experimental conditions were compared using Synergy KaleidaGraph (version 4.1.3) or Aabel NG2 v5 x64 (Gigawiz) as specified in each figure. Metal determinations were analyzed by estimation statistics using the web engine https:// www.estimationstats.com/\#/ (Ho et al., 2019).

\section{Results}

\section{P-ATPase copper transporters interact with the COG complex}

ATP7A and ATP7B are paralogs present in chordates, which originated from a single ATP7 gene found in the last common ancestor to eumetazoans. The Drosophila genus retained this single ATP7 gene (http://www.treefam.org/family/TF300460). We previously demonstrated that human ATP7A and the COG complex biochemically interact in cells (Comstra et al., 2017). Moreover, mutations of COG complex subunits reduced the expression of ATP7A and CTR1, resulting in cellular copper depletion (Comstra et al., 2017). As ATP7B shares 52.5\% identity with ATP7A (alignment of Uniprot entries ATP7A_HUMAN and ATP7B_HUMAN), then ATP7B may also interact with the COG complex. To test this hypothesis, we immunoprecipitated endogenous ATP7A or ATP7B from neuroblastoma or hepatoma human cell lines, respectively, and assessed the presence of COG complex subunits by immunoblot with antibodies against COG5 and COG7 (Fig. 1). Both ATP7A and ATP7B immunoprecipitated COG complex subunits (Fig. $1 A$, lane $4, B$, lanes 3 and 4). The selectivity of these ATP7A/B coprecipitations with COG subunits was determined with control immunoprecipitations with unrelated antibodies (Fig. $1 A$, lane $3, B$, lanes $3^{\prime}$ and $4^{\prime}$ ), out-competing immune complexes with the ATP7A antigenic peptide (Fig. 1A, lane 5), or by blotting ATP7B immunoprecipitates with GAPDH antibodies (Fig. 1B). Similar to ATP7A (Comstra et al., 2017), the association of ATP7B with the COG complex remained after challenging cells with excess extracellular copper (Fig. 1B, compare lanes 3 and 4). Downregulation of COG5 in hepatoma cells (Fig. 1C) disrupted Golgi morphology and decreased ATP7B expression, 


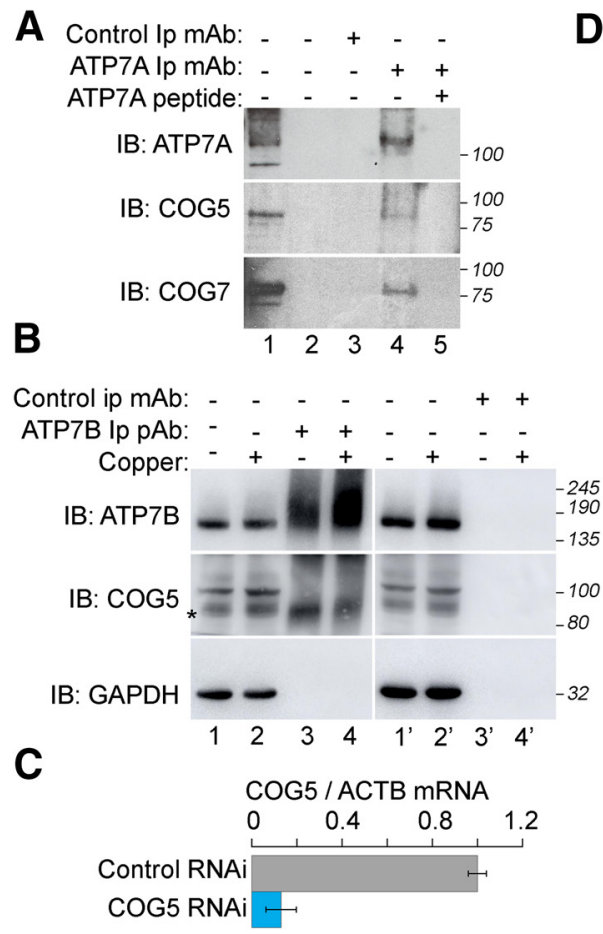

D
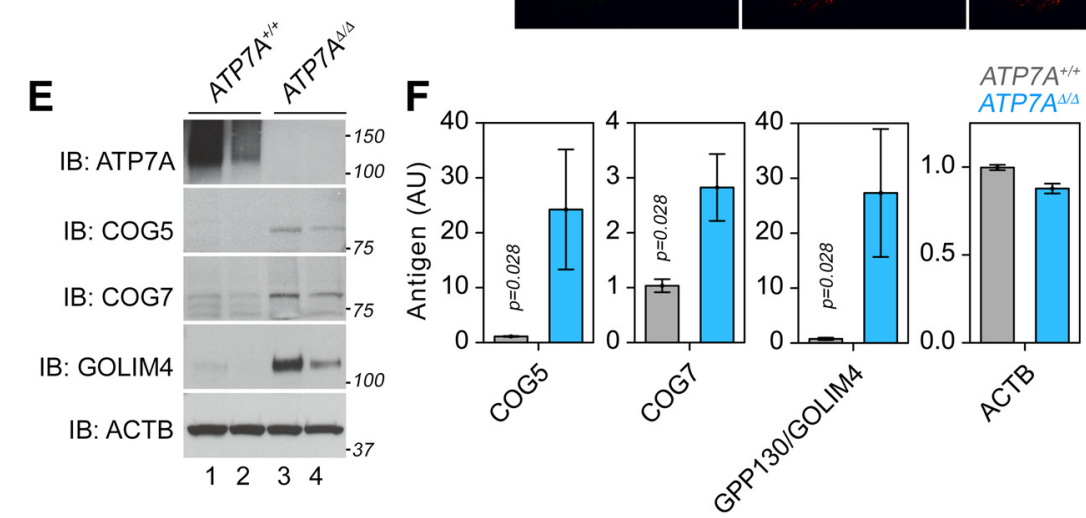

Figure 1. Biochemical and genetic interactions between COG complex subunits and ATP7 paralogs. SH-SY5Y $(\boldsymbol{A}, \boldsymbol{E}, \boldsymbol{F})$ and HepG2 $(\boldsymbol{B})$ cells were incubated in normal media or media supplemented with a $200 \mu \mathrm{m}$ copper excess ( $\boldsymbol{B}$, even lanes). Detergent soluble extracts from (A) SH-SY5Y and (B) HepG2 cells were immunoprecipitated with antibodies against ATP7A or ATP7B, respectively. The presence of COG complex in the immunoprecipitates was detected with antibodies against COG5 and COG7. Controls were performed with unrelated antibodies $\left(\boldsymbol{A}\right.$, lane 3 or $\boldsymbol{B}$, lanes $\left.3^{\prime}-4^{\prime}\right)$ or with the ATP7A antigenic peptide (A, lane 5). Asterisk marks non-specific band. $\boldsymbol{A}$, Lane 1 corresponds to input. $\boldsymbol{B}$, Lanes $1,2,1^{\prime}$ and $2^{\prime}$ correspond to inputs. $\boldsymbol{C}$, siRNA knock-down of COG5 in HepG2 cells. Relative expression corresponds to the ratio between COG5 and ACTB $(n=3)$. $\boldsymbol{D}$, Immunomicroscopy analysis of the expression and localization of ATP7B in Golgi (untreated cells) and lysosomes (CuSO ${ }_{4}$-treated cells). These compartments were detected with antibodies against GOLGIN97 and LAMP1, respectively. Scale bar: 10 $\mu$ m. E, ATP7A control (lanes 1-2) and null clone (lanes 3-4) cell extracts were immunoblotted with the indicated antibodies. $\boldsymbol{F}$, Quantification of blots presented in $\mathrm{E} ; n=4$ Wilcoxon-Mann-Whitney rank-sum test.

both at Golgi and lysosomal compartments after copperinduced translocation, as revealed by co-labeling cells with ATP7B and GOLGIN95 or LAMP1 antibodies, respectively (Fig. 1D). These findings demonstrate a conserved interaction between the COG complex with ATP7 paralogs.

Since mutations or RNAi downregulation of COG complex subunits reduced the expression of ATP7A or ATP7B (Comstra et al., 2017), we next asked whether the expression of COG subunits and GPP130/GOLIM4, an established COG-dependent Golgi resident protein, were sensitive to elimination of ATP7A expression. To address this question, we engineered SH-SY5Y neuroblastoma clones lacking ATP7A by CRISPR-Cas9 mutagenesis. We chose these cells because their ATP7B expression was undetectable by mass spectrometry analysis (V. Faundez' unpublished data). These ATP7A null clones robustly and significantly increased the expression of the COG complex subunits COG5 and seven as well as a Golgi resident and COG-interacting protein GPP130/GOLIM4 (Fig. 1E,F; Oka et al., 2004; Zolov and Lupashin, 2005; Sohda et al., 2010; Comstra et al., 2017). These findings demonstrate bidirectional genetic control of ATP7 and COG complex machinery expression.

\section{Synaptic development requires ATP7-dependent and} COG-dependent copper homeostasis

We tested the phylogenetic conservation of the interactions between the COG complex and copper transporters in adult and developing Drosophila neurons. We took advantage of the fact that the expression of mammalian ATP7A, ATP7B, and CTR1 is reduced in cells that lack COG complex subunits (Fig. 1C,D; Comstra et al., 2017). We reasoned that Drosophila neurons would help us to genetically test whether the COG complex balances the expression of Drosophila ATP7 and CTR1 to control copper homeostasis. We predicted that neuronal cell autonomous and systemic changes in transporter expression should 

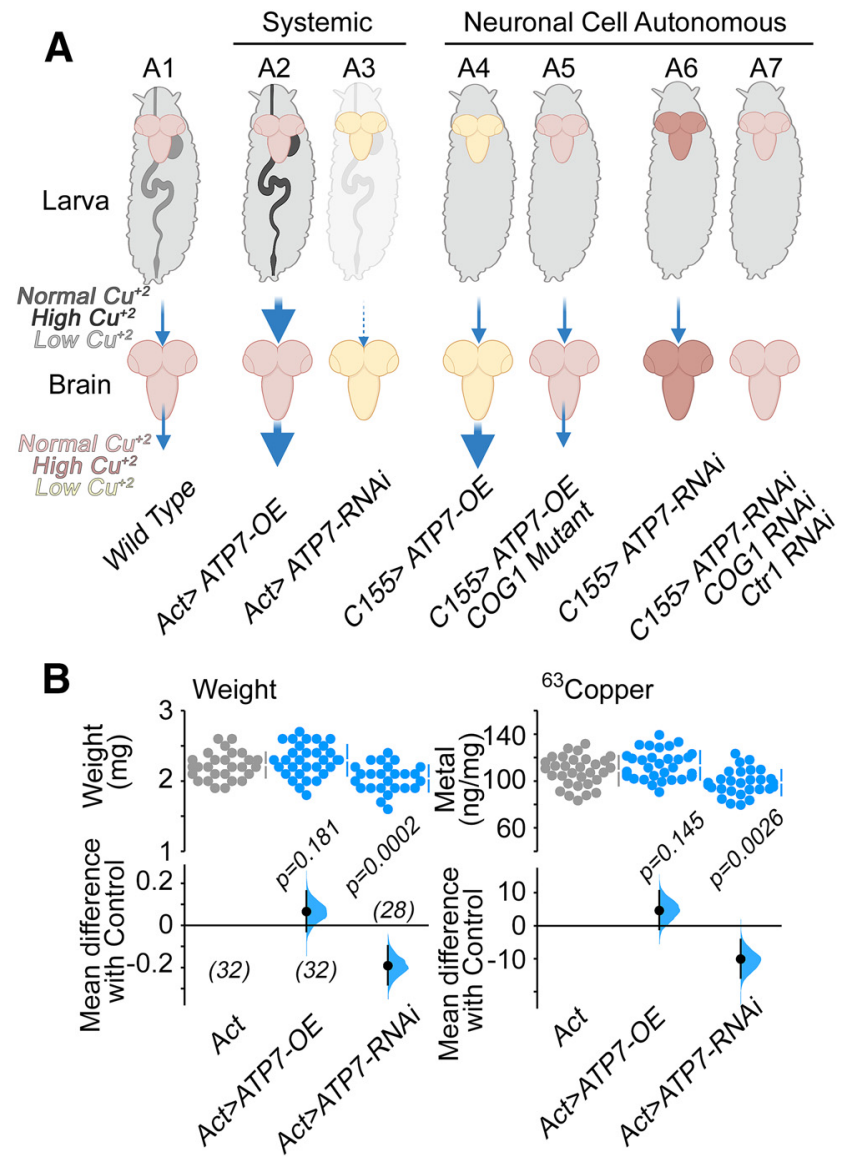

Figure 2. Model of copper homeostasis by the COG complex and copper transporters and copper content in Drosophila. A, Model of predicted larval and brain copper status in different genotypes. Brain and gut are depicted in systemic genetic models, while only brain is depicted in the neuronal cell autonomous models. Color intensities of organs show predicted copper content (color code in the left of the figure). Magnitude of brain copper influx and efflux are depicted in the size of blue arrows in the bottom row. Note that changes in copper content in brain and whole larvae can be independently modulated by neuronal cell autonomous ( $(155>$ ) or systemic (actin driver, Act $>$ ) modifications of ATP7 gene expression. $\boldsymbol{B}$, ICP-MS determinations of total larval copper content in UAS-ATP7 or UAS-ATP7 RNAi transgenes expressed from a ubiquitous Actin-GAL4 driver. The mean difference for two comparisons against the shared control Act are shown in the above Cumming estimation plot. The raw data are plotted on the upper axes. On the lower axes, mean differences are plotted as bootstrap sampling distributions. Each mean difference is depicted as a dot. Each $95 \%$ confidence interval is indicated by the ends of the vertical error bars. The $p$ value of the two-sided permutation $t$ test is indicated. The number of larvae analyzed is depicted by italic figures in parentheses.

differentially and predictably affect copper content in developing tissues and animals (Fig. 2A). For example, neuronal cell autonomous ATP7 overexpression would decrease cellular copper by localizing this transporter to the plasma membrane, thus constituting a model of copper depletion by metal efflux (Fig. 2A4; Norgate et al., 2006; Burke et al., 2008; Binks et al., 2010). In contrast, copper content after systemic ATP7 overexpression at the plasma membrane would result from a balance between two effects (Fig. 2A2). First, an increased enterocyte copper absorption resulting in increased copper in the hemolymph bathing cells in the organism (Fig. 2A2). This enterocyte-hemolymph effect would be counterbalanced by increased cellular copper efflux from internal organ cells, such as neurons (Fig. 2A2; Bahadorani et al., 2010). Conversely, neuronal cell autonomous ATP7 knock-down would increase cellular copper because of defective copper efflux from neurons (Fig. 2A6; Norgate et al.,
2006; Burke et al., 2008; Binks et al., 2010). However, systemic ATP7 inhibition would be dominated by enterocyte copper absorption defects, hemolymph copper deficiency, and organ copper depletion, thus mimicking Menkes disease (Fig. 2A3). We tested these copper content predictions by systemic overexpression of ATP7 or downregulation of ATP7 in all tissues using the Actin-GAL4 driver (Fig. 2B). Systemic overexpression of ATP7 did not significantly modified the larval copper content per mg of larva (Fig. 2B). In contrast, ubiquitously expressed ATP7 RNAi transgene decreased copper content per mg of larva although these larvae were significantly smaller (Fig. 2B). This ATP7 RNAi copper content phenotype partially mimics the organismal copper depletion phenotype observed in Menkes disease (Figs. 2A3,B).

To determine whether systemic ATP7 overexpression affects synaptic structure, we analyzed neuromuscular junction morphology and found that overexpression of ATP7 had no effect on synapse size (Figs. $2 A 2,3 A, B$ ). In contrast, flies heterozygous for COG1 had increased synapse size measured as the total length of all branches (Fig. $3 A, B, C O G 1^{e 02840 /+}$ ), a phenotype rescued by overexpression of ATP7 (Fig. 3A,B). This result suggests that the effects of reduced COG1 expression are due in part to the COG effects on endogenous ATP7 expression (Fig. $3 A, B$ ). If loss of COG1 results in reduced ATP7 expression, then phenotypes caused by neuronal cell autonomous ATP7 overexpression should be reverted by either systemic or neuronal-selective downregulation of the COG1 subunit (compare Fig. $2 A 4$ and A5). We find that neuronal-specific overexpression of ATP7 using C155-GAL4 results in decreased synapse size (Fig. $3 C, D$ ), and this phenotype was rescued by either COG1 heterozygosity or neuronal-specific knock-down of COG1 (Fig. $3 C, D)$. Second, we manipulated the expression of CTR1 and the COG complex cell autonomously in larval motor neurons in which ATP7 expression is downregulated (Figs. $2 A 7,3 E-G)$. Neuron-specific downregulation of ATP7 did not change the neuromuscular junction size (Fig. $3 E, F)$ but increased the size of synaptic boutons (Figs. $2 A 6,3 E$, G, insert). This phenotype was rescued by either neuronal-specific COG1 or CTR1 knock-down, indicating that COG1 downregulation modulates the entry of copper from the plasma membrane phenocopying CTR1 downregulation (Figs. 2A7, 3E,G). These results demonstrate that the COG complex regulates cellular copper homeostasis by controlling the function of ATP7 and CTR1 in developing motor neurons.

To assess whether ATP7 and COG genetic interactions modulating synapses were just restricted to developing motor neurons, we measured dendritic arborization (da) complexity in Drosophila third-instar larvae class IV (C-IV) da epidermal sensory neurons (Fig. 4). The C-IV da neuron possesses an elaborated and stereotypic dendritic arbor whose complexity is responsive to gene perturbations (Iyer et al., 2013a; Singhania and Grueber, 2014; Das et al., 2017). We overexpressed ATP7 in a neuronal cell-autonomous manner, a model of copper efflux (Fig. 2A4), using the ppk-GAL4 driver (Yang et al., 2009). ATP7 expression significantly decreased the complexity of the dendritic arbor, as determined by the total dendritic length and number of branches (Fig. $4 A-C$ ). COG1 haploinsufficiency with the $C O G 1^{e 02840 /+}$ allele did not significantly change dendritic arbors (Fig. $4 A-C)$. However, this COG1 gene dosage reduction was enough for suppressing the ATP7 overexpression dendritic phenotype (Figs. 2A5, 4A-C). The dendritic phenotype 
A
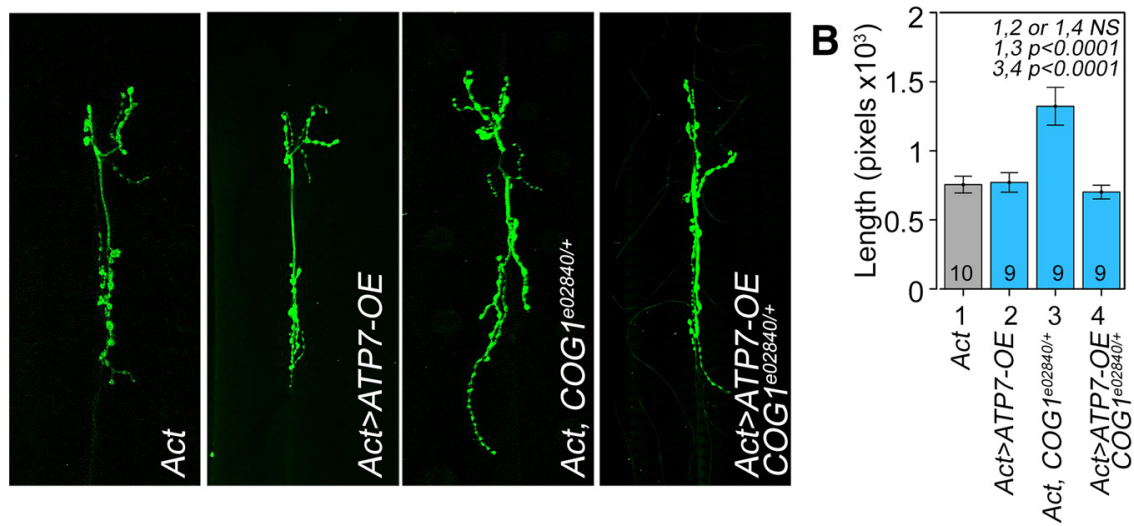

C
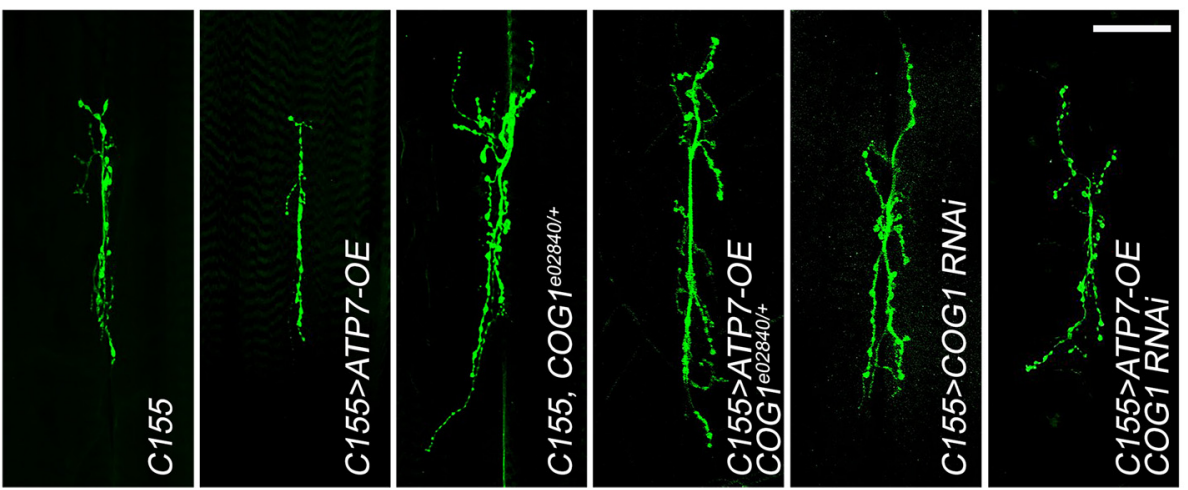

$\mathbf{E}$
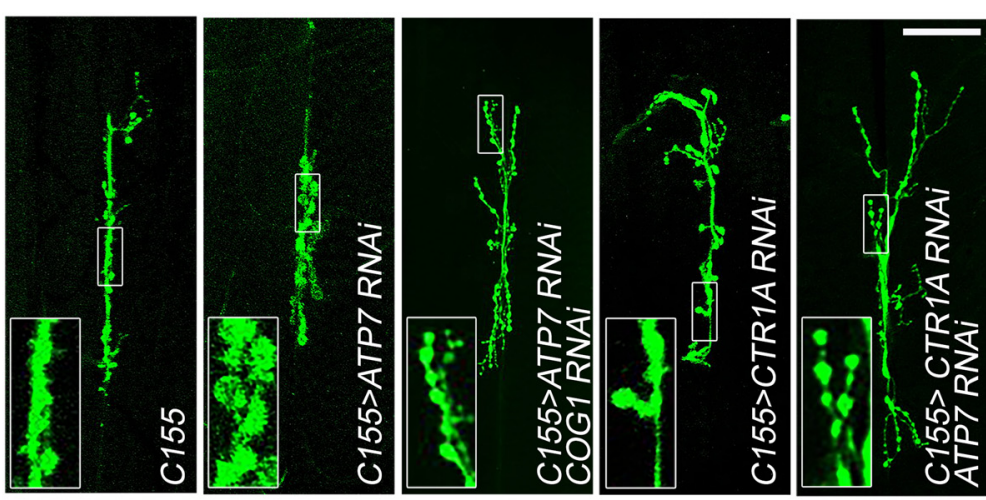

D

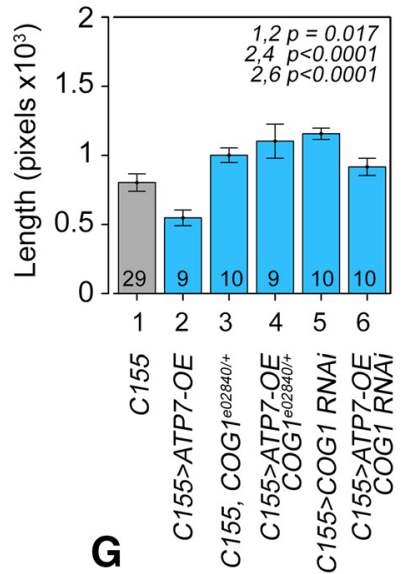

$\mathbf{F}$

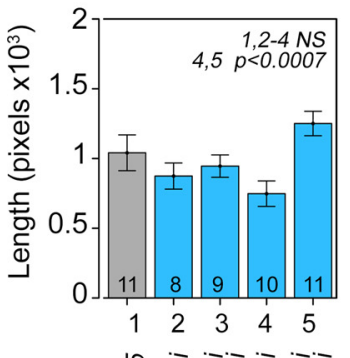

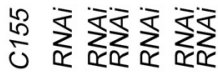

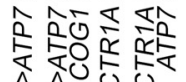

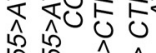

¿ य

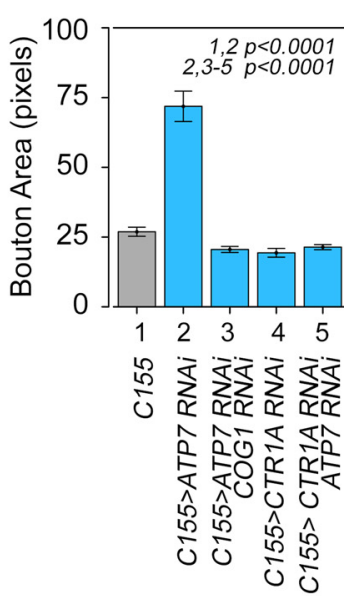

Figure 3. Copper homeostasis by the COG complex and copper transporters modulate glutamatergic synapse morphology. Muscle 6-7 neuromuscular junctions from wild-type animals and animals expressing ATP7, COG, and CTR1 UAS-transgenes stained with anti-HRP antibodies $(\boldsymbol{A}, \boldsymbol{C}, \boldsymbol{E})$. $\boldsymbol{C}$, Synapses from animals carrying the UAS-ATP7 transgene expressed under the systemic driver Actin-GAL4, the $\mathrm{COG}^{\mathrm{eO2} 840 /+}$ genotype, each in isolation or their combination. Scale bar: $50 \mu \mathrm{m}$. $\boldsymbol{B}$, Total branch length quantifications of animals in $\boldsymbol{A}$. $\boldsymbol{C}$, Synapses from animals carrying the UAS-ATP7 transgene, UAS-COG1 RNAi expressed under the C155-GAL4 driver, or the COG1 $7^{\text {e02840/+ }}$ genotype, each in isolation or their combinations. D, Quantifications of animals in C. E, Synapses from animals carrying the UAS-ATP7 RNAi, UAS-CTR1 RNAi expressed with the C155-GAL4 driver, or their combinations. $\boldsymbol{F}$, G, Total branch length and bouton size area quantifications, respectively, of animals in $\boldsymbol{E}$. Number of animals per genotype $(n)$ are presented by the number at the base each column. One-way ANOVA followed by two-tailed Fisher's least significant difference comparison.

caused by ATP7 overexpression and its rescue were more prominent in terminal branches, as indicated by the reversed Strahler analysis, in which distal branches of the 1 and 2 categories were the most affected as compared with branches closer to the cell body (Fig. 4D). These results demonstrate that the COG complex balances the expression of copper influx and efflux transport activities from cells (compare Fig. $2 A 4, A 5)$. In turn, these changes in copper homeostasis modulate dendritic and presynaptic morphology in diverse developing neuronal types.
The COG complex genetically interacts with ATP7 transporters in adult Drosophila tissues

We applied the same experimental logic used for larval synapses to adult Drosophila catecholaminergic and serotoninergic neurons. These cells are only sensitive to ATP7 expression manipulation when the animals are exposed to excess dietary copper (Comstra et al., 2017). We focused on these cells because copperdependent molecules and transporters are highly expressed in vertebrate catecholaminergic cells (Xiao et al., 2018). As we previously demonstrated, copper feeding control animals increased 

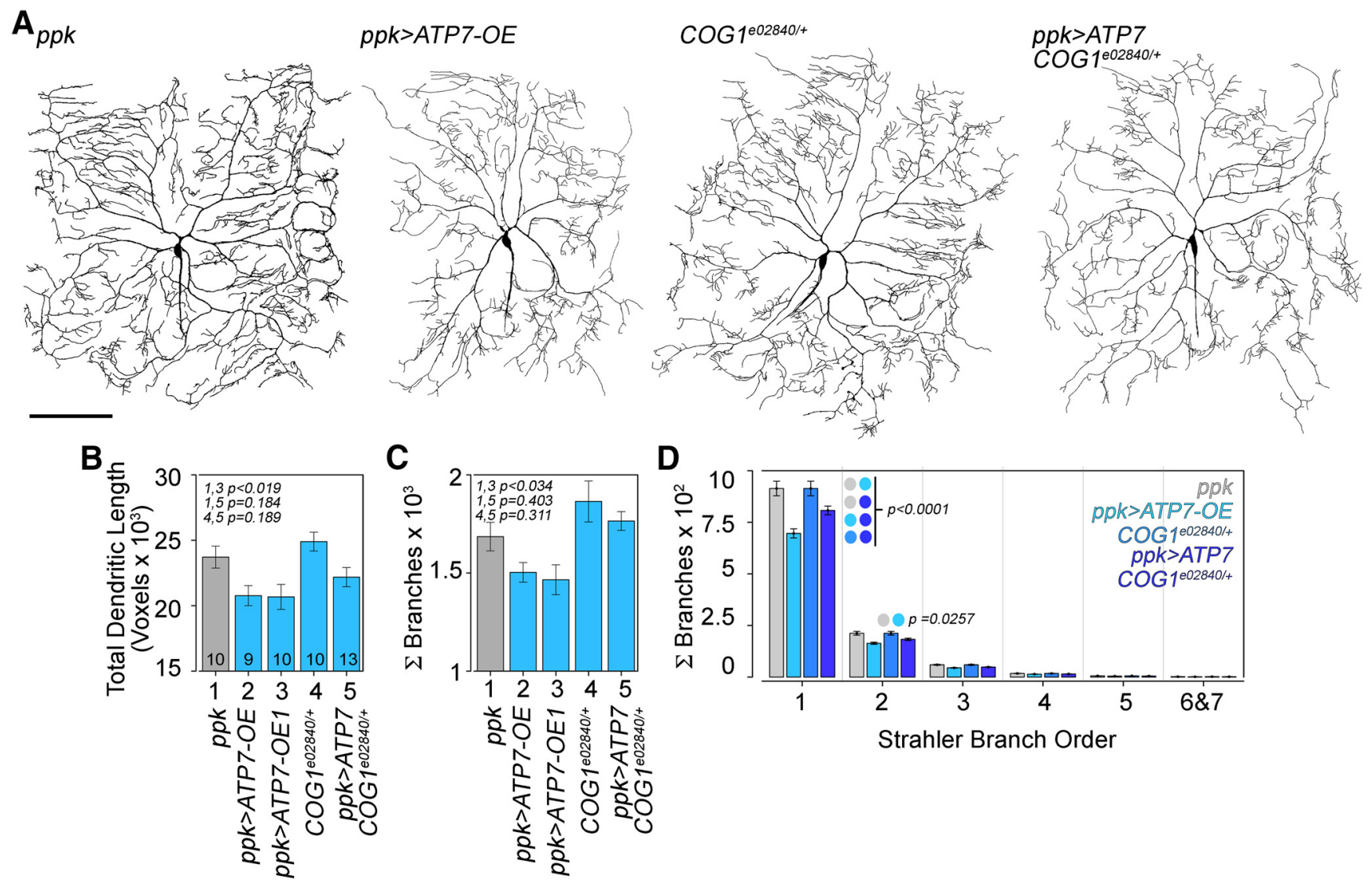

Figure 4. The COG complex and ATP7 modulate sensory C-IV da neuron dendrite architecture. $A$, Representative live confocal images of C-IV da neurons of the specified genotypes labeled by GFP driven by CIV-GAL4 (477;ppk). B-D, Quantitative analysis of total dendritic length and total number of branches in the specified genotypes. OE and $0 \mathrm{E} 1$ represent different transgenic animal strains overexpressing ATP7 (Norgate et al., 2006). Scale bar: $200 \mu \mathrm{m}$. D, Reversed Strahler branch order analysis. Terminal branches correspond to Strahler numbers 1 and 2. Average $\pm \mathrm{SEM} n$ of animals per genotype are presented by the number at the base each column. For $B, C$, comparisons were made with one-way ANOVA followed by two-tailed Fisher's least significant difference comparison. $\boldsymbol{D}$, Analysis was made with two-way ANOVA followed by Tukey's multiple comparisons test.

mortality close to a $100 \%$ (Fig. $5 A$, column 1; Comstra et al., 2017). We used the Ddc-GAL4 driver to overexpress ATP7 in catecholaminergic and serotoninergic neurons. However, this driver is also expressed in larval epidermis ( $\mathrm{Li}$ et al., 2000; Landgraf et al., 2003). ATP7 overexpression using the DdcGAL4 driver decreased copper-induced mortality close to $30 \%$ and $60 \%$ in adult females and males, respectively (Fig. $5 \mathrm{~A}$, columns 1 and 2). We interpret this protective effect as an increased copper efflux because of overexpressed ATP7 (Fig. 2A4). A similar protective outcome was achieved by downregulation of the COG1, COG5, or COG8 subunits (Fig. 5A, column 1 compare to 3,5 , and 7 ). Here, the protective effect of COG downregulation likely uncovers a decreased CTR1 activity necessary for copper influx into aminergic neurons (Comstra et al., 2017). To define how the COG complex balances the expression of ATP7 and a CTR1 activity, we downregulated COG complex subunits in the ATP7 overexpression background and find that this leads to increased mortality as compared with the COG subunit RNAi alone (Fig. 5A, compare columns 3-4 and 7-8), suggesting that the COG complex preferentially affects the expression of ATP7 over a copper uptake transporter activity (compare Fig. $2 A 4$ and A5). If the COG complex has a stronger influence on ATP7 than CTR1 in aminergic neurons, then knock-down of ATP7, a model of neuronal copper accumulation (Fig. 2A6), should not protect animals after a copper feeding challenge. Additionally, the ATP7 knock-down phenotype should be suppressed by inhibition of the COG complex because of disruption of copper influx mechanisms (Fig. 2A7; Comstra et al., 2017). As predicted, ATP7 RNAi-driven mortality was indistinguishable from wild-type animals (Fig. 5B, compare columns 1 and 2). However, the effect of copper feeding on mortality were suppressed by inhibition of the COG subunits alone or in combination with inhibition of ATP7 (Fig. 5B, compare columns 3-4,5-6, and 7-8). These results demonstrate that in neurons expressing ATP7, COG complex deficiency preferentially suppresses the effects of ATP7 overexpression (Fig. 2A5). These findings demonstrate the COG complex balances cellular copper homeostasis by modulating the expression of ATP7 and copper influx activity, presumably through CTR1.

We validated these genetic interactions and their interpretations in the Drosophila adult epidermis where the interplay of ATP7 and CTR1 in controlling copper homeostasis has been precisely established. In this tissue, overexpression of ATP7 with the epidermal pnr-GAL4 driver depletes cellular copper, a phenomenon rescued by increased expression of the plasma membrane copper uptake transporter CTR1 (Norgate et al., 2006; Burke et al., 2008; Binks et al., 2010; Hwang et al., 2014; Mercer et al., 2016). We reasoned that, in contrast with neurons, phenotypes caused by epidermal overexpressed ATP7 would be additive with epidermal COG complex subunit RNAi because of downregulation of a postulated CTR1 copper influx activity. Thus, supporting the concept that copper homeostasis is chiefly controlled through a putative CTR1 activity in the epidermis (Extended Data Fig. 5-1). Overexpression of ATP7 caused 
incomplete dorsal closure and depigmentation of the thorax and abdomen of adult female and males flies (Extended Data Fig. 5-1A). These phenotypes were maladaptive, as demonstrated by decreased animal survival to $\sim 38 \%$ and $\sim 65 \%$ in adult females and males, respectively (Extended Data Fig. 5-1B, column 2). These ATP7-dependent epidermal phenotypes were absent in animals where the expression of the COG complex was reduced by RNAi against any one of three COG subunits (Extended Data Fig. 5-1B, column 3). However, simultaneous expression of ATP7 in animals where the COG complex was downregulated by RNAi significantly decreased survival to $\sim 22 \%$ and $\sim 35 \%$ in adult females and males, respectively (Extended Data Fig. 5-1B, column 4). This doubling in mortality represents an additive phenotype. These results suggest that the COG complex modulates copper homeostasis by preferentially controlling the expression of a copper influx activity, possibly CTR1, in epidermal cells (Extended Data Fig. 5-1C). These epidermal findings further validate our genetic strategy to examine whether an intact COG complex is required for balancing copper influx and efflux in neurons.

\section{Mitochondrial respiration requires a COG- dependent and copper-dependent mechanisms} A possible target of copper dyshomeostasis in motor and sensory Drosophila neurons is the mitochondria as both genetic defects in ATP7A and ATP7B perturb mitochondrial morphology and function (Yoshimura and Kudo, 1983; Yamano and Suzuki, 1985; Onaga et al., 1987; Yamano et al., 1988; Gu et al., 2000; Zischka et al., 2011; Bhattacharjee et al., 2016; Lichtmannegger et al., 2016; Guthrie et al., 2020). Similarly, COG complex mutants decrease tetrazolium salt metabolization mediated by the $\mathrm{NAD}(\mathrm{P}) \mathrm{H}$-dependent oxidoreductase and dehydrogenase enzymes, which localize both to the cytoplasm and mitochondria (Berridge et al., 2005; Comstra et al., 2017). This suggests that the COG complex could modulate mitochondrial function in a copper-dependent manner. We tested this hypothesis using a combination of phylogenetic-bioinformatic analyses, measuring mitochondrial respiration with Seahorse oximetry, and biochemical approaches.

We used evolutionary rate covariation to determine functional associations between either the ATP7A and ATP7B proteins or the COG complex with subunits of each one of the five mitochondrial respiratory chain complexes. This approach allows us to examine coevolutionary forces that act on genes even when their products do not physically interact or may reside in different compartments (Fig. 6A,B, ERC; Clark et al., 2012, 2013; Findlay et al., 2014). The phylogenic correlation between ATP7A and ATP7B was significant with mitochondrial Complexes I, III, and IV, the latter, a copper-containing respiratory chain complex (Fig. 6A; Horn and Barrientos, 2008). Moreover, the eight subunits of the COG complex also covaried significantly with Complex I (Fig. 6A). We analyzed the evolutionary rate covariation among all pairs of a gene group integrated by ATP7A, ATP7B, the COG complex, and the mitochondrial Complex I subunits. Gene group analysis of the evolutionary rate covariation among these 48 genes indicated that this gene set is significantly correlated phylogenetically (Fig.
$6 B, p=0.00130$ ). Also, pairwise analyses showed that ATP7A coevolved with ATP7B (evolutionary rate covariation scores $>0.3, p<0.05$ ), and multiple Complex I subunits (Fig. 6B,C). Conversely, COG complex subunits significantly coevolved with ATP7B, and Complex I subunits (Fig. 6B,C). These results support a model where ATP7A, ATP7B, and the COG complex participate in a pathway shared with mitochondria.

We tested whether COG genetic defects could impair mitochondrial function by measuring oxygen consumption rates with Seahorse ${ }^{\mathrm{TM}}$ technology (Divakaruni et al., 2014). We used HEK293 cells where both genomic copies of the COG subunits 1 $\left(\mathrm{COG}^{\Delta / \Delta}\right)$ or $8\left(\mathrm{COG}^{\Delta / \Delta}\right)$ genes were edited by CRISPR-Cas 9 (Bailey Blackburn et al., 2016; Blackburn and Lupashin, 2016). These COG null cells phenocopy established COG complex deficiency phenotypes, which include defective Golgi-dependent glycosylation of membrane proteins and their degradation in lysosomal compartments (Shestakova et al., 2006; Bailey Blackburn et al., 2016; Blackburn and Lupashin, 2016). COG null HEK293 cells had a lower basal oxygen consumption rate compared with wild-type controls (Fig. 6D,E). To determine whether this reduced basal respiration is because of impaired copper availability, we treated cells with disulfiram, a drug with several targets and also a copper ionophore (Allensworth et al., 2015; https://go.drugbank.com/drugs/DB00822). We find that the basal respiration rate in wild-type cells in the presence of 180 nм copper was not changed even after $4 \mathrm{~h}$ (Fig. $6 D, F$, acute response). In contrast, the addition of copper-disulfiram to $\mathrm{COG}^{\Delta / \Delta}$ and COG8 ${ }^{\Delta / \Delta}$ HEK293 cells significantly improved the basal respiration rate, a response that was evident at $2 \mathrm{~h}$ and progressively increased up to $4 \mathrm{~h}$ of incubation with copper- 


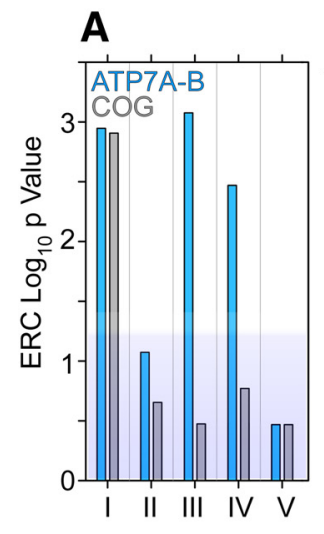

B $-1=0.3 \quad 1-E R C$
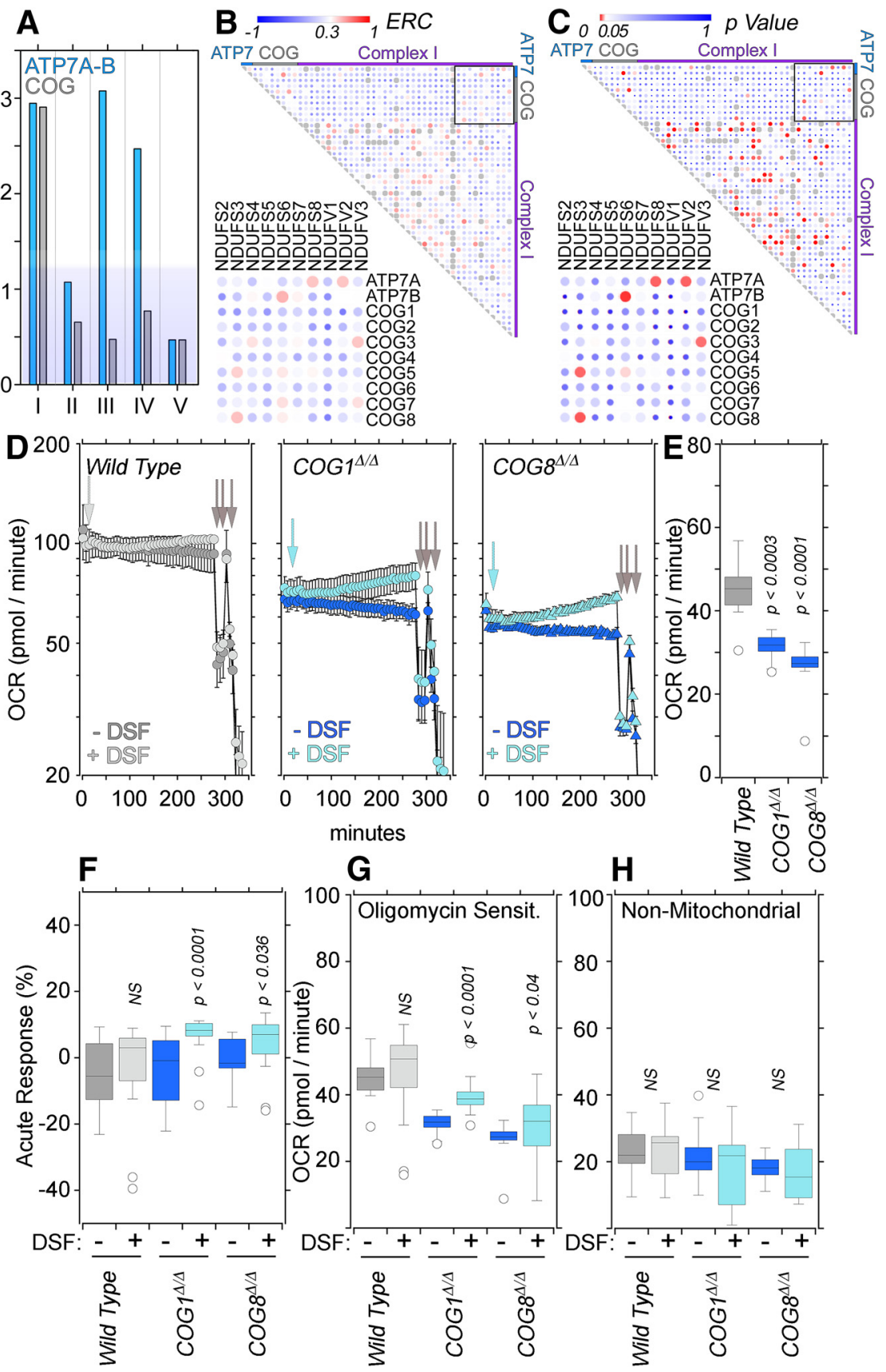

G

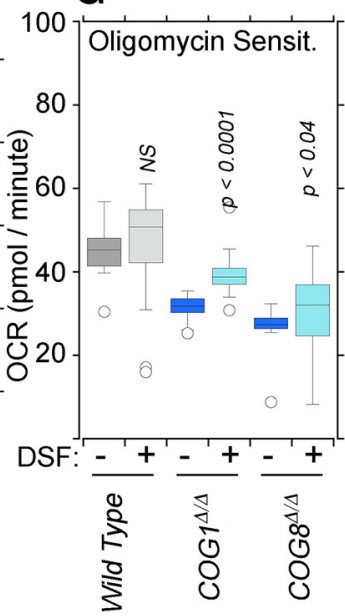

H

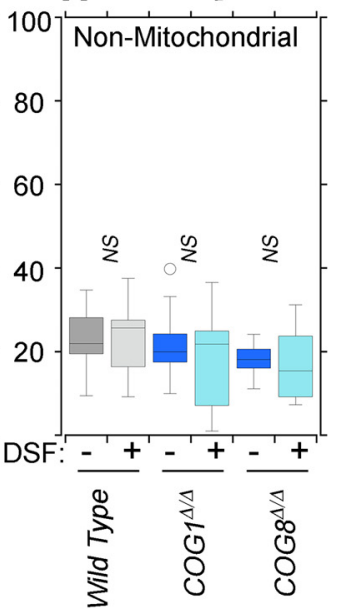

Figure 6. The COG complex activity is required for mitochondrial respiration. $A-C$, Evolutionary rate covariation (ERC) between gene groups constituted by human ATP7A and ATP7B or the COG complex subunits with subunits of the five mitochondrial respiratory complexes defined by the CORUM database. $A$, Group probability of evolutionary covariation. $B$, ERC for pairs of genes in a gene group that includes ATP7A and ATP7B, the eight COG complex subunits, and the 38 nuclear encoded subunits of the mitochondrial respiratory Complex I (CORUM complex ID:388). ERC threshold $>0.3$ identifies covariated gene pairs. $\boldsymbol{C}, p$ values for genes pairs presented in $\boldsymbol{B} ; \alpha<0.05$ Wilcoxon rank-sum test against 100,000 permutations. ERC and $p$ values are represented by circle color and size. $\mathbf{D}-\boldsymbol{H}, \mathrm{CO}$ null cells have defective respiration that can be ameliorated with a copper ionophore. Extracellular Seahorse flow oxymetry was used to measure oxygen consumption rate (OCR) in wild-type, $\mathrm{COG}^{1 / \Delta}$, and $\mathrm{COG}^{8^{\Delta / \Delta}}$ HEK293 cells with or without the addition of $100 \mathrm{~nm}$ disulfiram in the presence of $180 \mathrm{~nm}$ copper. (D) OCR each time points over $300 \mathrm{~min}$. $\boldsymbol{E}$, Average basal OCR. F, Acute response. Mitochondrial respiration was isolated by the addition of $0.1 \mu \mathrm{m}$ oligomycin $(G)$, and non-mitochondrial respiration was measured by the addition of $0.5 \mu \mathrm{m}$ rotenone and antimycin $\mathrm{A}(\boldsymbol{H}) . N=4$, non-parametric Kruskal-Wallis test followed by pairwise Mann-Whitney $U$ test comparisons. See Extended Data Figure 6-1.

ionophore (Fig. $6 D, F$, acute response). This selective improvement in oxygen consumption by COG null cells was sensitive to the mitochondrial ATPase inhibitor oligomycin (Divakaruni et al., 2014), thus demonstrating the mitochondrial origin of the copper-disulfiram rescue of the respiration phenotype in COG-null HEK293 cells (Fig. 6D,G). Non-mitochondrial sources of oxygen consumption were not affected by genotype or copper ionophore addition, as determined by measuring oxygen consumption in the presence of antimycin and rotenone, inhibitors of cytochrome $\mathrm{C}$ reductase and Complex I, respectively (Fig. 6D,H; Divakaruni et al., 2014). These results demonstrate that mitochondrial respiration defects observed in COG-deficient cells can be acutely corrected by circumventing impaired copper transport with a copper ionophore.

We next asked whether these mitochondrial functional defects in COG mutant cells correlated with changes in mitochondria composition and/or morphology. A proteome of COG mutant cell membranes identified $\sim 13 \%$ of mitochondria annotated proteins among all significant COG-sensitive hits (V. Lupashin's unpublished data). We used this dataset to inform a selection of mitochondria-localized proteins to assess their expression in COG1 and COG8 mutant cells. These selected mitochondrial proteins include copper-delivery factors to Complex IV in the electron transport chain (COX11 and COX17; Baker et al., 2017), mitofusin (MFN1; Detmer and Chan, 2007), the pyruvate carrier MPC1 (Bricker et al., 2012), and a mitochondrial protein involved in cholesterol metabolism (DHCR24). These five proteins were annotated to mitochondria by Mitocarta 2.0 (Calvo et al., 2016). Moreover, these five proteins increased their content in COG1 and COG8 null cells as compared with wild-type cells (Extended Data Fig. 6-1A). Despite the Seahorse and biochemical mitochondrial phenotypes in COG null cells, we could not detect alterations in the morphology of mitochondria as revealed by immunofluorescence microscopy of wild-type and COG1 null cells (Extended Data Fig. 6-1B). Thus, phylogenetic, functional, and biochemical results show that COG complex-dependent copper homeostasis is necessary for mitochondrial integrity.

\section{ATP7-dependent and COG-dependent copper homeostasis sustain mitochondrial synaptic content}

We sought to answer whether ATP7-dependent and COG-dependent copper homeostasis was required for normal Drosophila mitochondria at motor neuron synapses. To address this question, we generated animals carrying both UAS-ATP7 and a UAS-mitochondriatargeted GFP reporter (Fig. 7, MitoGFP), under the control of the C155-Gal-4 neuronal driver. We focused on the neuronal ATP7 

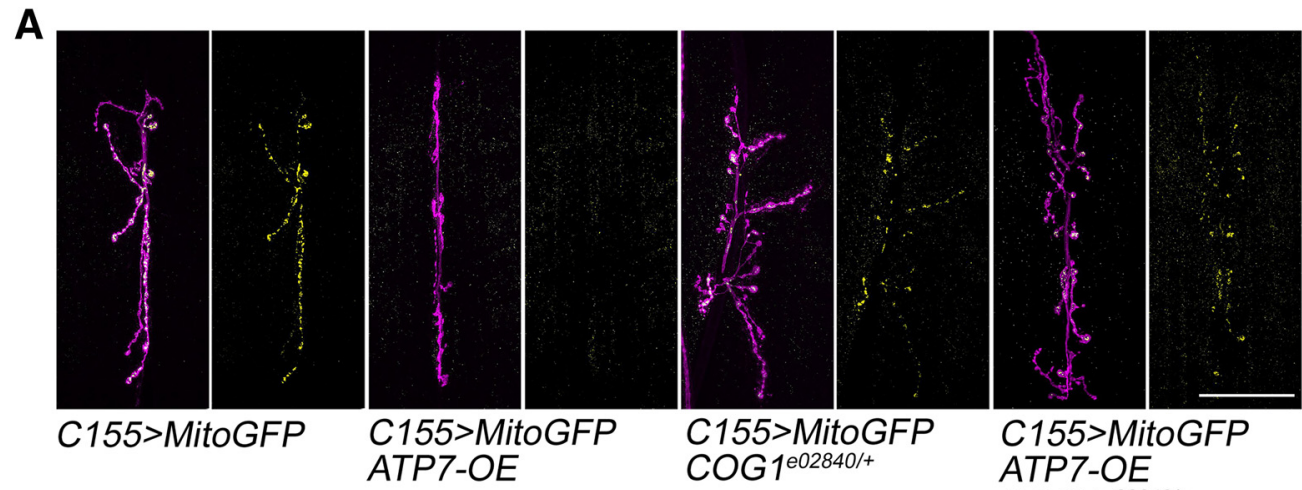

B
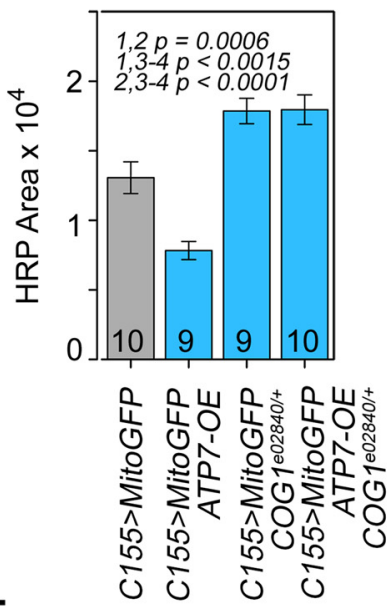

C
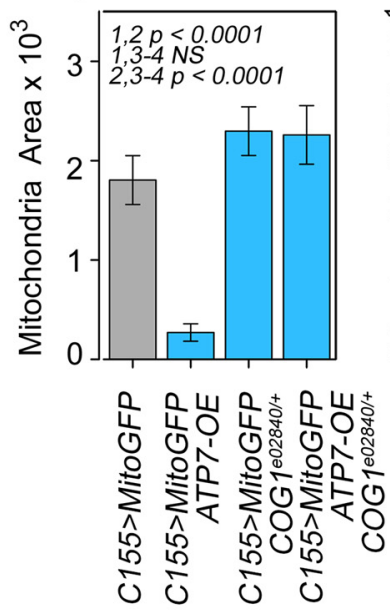

C155>MitoGFP ATP7-OE

\section{E}
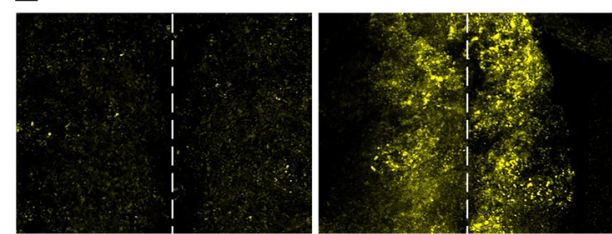

C155>MitoGFP

C155>Mito GFP ATP7-OE
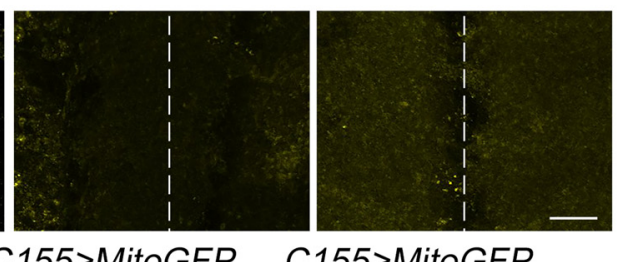

C155>MitoGFP COG $1^{102840 /+}$
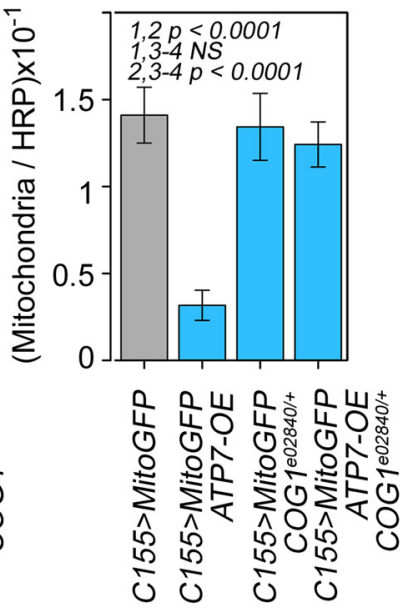

Figure 7. The COG complex and ATP7 are required to maintain mitochondrial content in glutamatergic synapses. $A, B$, Muscle $6-7$ neuromuscular junctions from third-instar larvae from wild-type animals and animals expressing ATP7 transgene, carrying the COG1 $7^{\text {e2840/+ }}$ allele or the combination were crossed to the mitochondrial UAS-mitochondrial-GFP reporter. Reporter genes were expressed with the neuronal C155-GAL4 driver. Dissected larvae were stained with anti-HRP antibodies and anti-GFP. Scale bar: $50 \mu$ m. $\boldsymbol{B}$-D, Quantification of synaptic branches and mitochondria content expressed as HRP or GFP area and their ratios. Average \pm SEM $n$ of animals per genotype are presented by the number at the base each column. One-way ANOVA followed by two-tailed Fisher's least significant difference comparison. $\boldsymbol{E}$, Third-instar larvae from wild-type animals and animals expressing ATP7 transgene, carrying the COG $7^{\text {e02840/+ }}$ allele, or their combination were crossed to the mitochondrial UASGFP reporter. Transgenes were expressed with the neuronal C155-GAL4 driver. Dissected ventral cords were stained with anti-GFP and imaged by confocal microscopy. Scale bar: $25 \mu \mathrm{m}$.

overexpression/copper efflux paradigm because ATP7 overexpression synaptic phenotypes are robustly rescued just by a single gene copy loss of COG1 (Figs. 2A4,A5, 3C,D). We measured synapse morphology on neuromuscular junctions double-stained with antibodies against HRP and GFP to label the neuronal plasma membrane and mitochondria, respectively. Mitochondria were present in neuromuscular junctions, including muscles 6 and 7 , a standard synaptic model (Fig. 7A). A single copy loss of the COG1 gene is not sufficient to alter mitochondrial content and distribution in neurons (Fig. 7A-D) even when the COG1 haploinsufficiency increased synapse branching $\left(C O G 1^{e 02840 /+}\right.$; Fig. $7 A, B)$. In contrast, ATP7 overexpression in neurons resulted in a nearly complete depletion of mitochondria from synapses (Figs. $2 A 4,7 A, C, D$ ) with a concomitant increase in mitochondrial signal at ventral nerve cords, a site where motor neuron cell bodies reside (Fig. 7E). This pronounced mitochondrial synapse depletion phenotype was rescued in animals where the UAS-ATP7 transgene is expressed in the $C O G 1^{e 02840 /+}$ background (compare Figs. $2 A 4$ and $2 A 5,7 A, C$, $D)$. The $C O G 1^{e 02840 /+}$-dependent rescue of the ATP7 overexpression mitochondrial phenotype also resulted in a normalization of the mitochondrial signal in the ventral nerve cord (Fig. 7E).

In parallel, we conducted analyses in Drosophila third-instar larvae C-IV da neurons by overexpressing ATP7A, the plasma membrane marker CD4-tdTomato, and MitoGFP in a cell-autonomous manner using the 477-GAL4 and ppk-GAL4 drivers (Fig. 8). ATP7 overexpression decreased the mitochondrial content in dendrites (Figs. $2 A 4,8 A-C$ ). This phenotype was partially rescued by the $C O G 1^{e 02840 /+}$ allele (Figs. $2 A 5,8 A$ ), as indicated by a restoration of the mitochondria numbers at branch points of the dendritic tree (Fig. 8C). These results demonstrate that ATP7, 
A

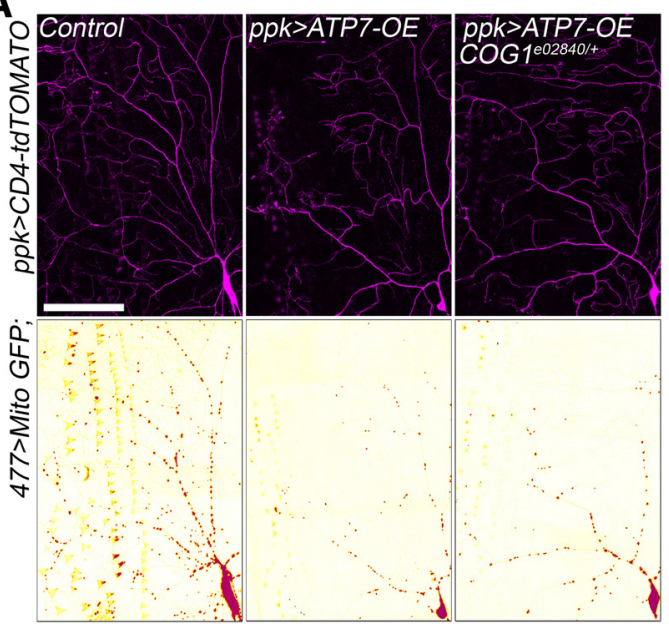

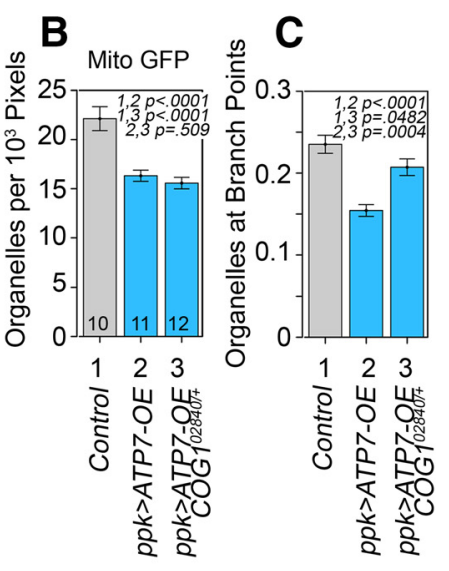

Figure 8. The COG complex and ATP7 are required to maintain mitochondria in sensory C-IV da neuron dendrites. $\boldsymbol{A}$, Representative live confocal images of C-IV da neurons of the specified genotypes expressing a mitochondria-targeted GFP UAS-transgene and a UAS-plasma membrane marker (CD4-td-Tomato) under the control of the 477-GAL4 driver. B, C, Quantification of mitochondria content as organelles per branch length unit or as organelles at branching points. Scale bar: $100 \mu \mathrm{m}$. Average \pm SEM $\mathrm{n}$ of animals per genotype are presented by the number at the base each column. One-way ANOVA followed by two-tailed Fisher's least significant difference comparison.

COG, and their interactions modulate dendrite and presynaptic mitochondrial content in motor and sensory neurons. These ATP7 and COG-dependent synaptic branching and mitochondrial phenotypes predict intricate alterations in synaptic transmission and plasticity in neurons with copper dyshomeostasis.

\section{The COG complex and ATP7 modulate basal release probability}

We analyzed the effects of single or combined changes in the expression of ATP7 and the COG complex with the COG1 $1^{e 02840 /+}$ allele on neurotransmission (Figs. 2A4, A5, 9-10). We measured synaptic transmission at the neuromuscular junction of Drosophila larvae synapses on muscles 6-7 under two-electrode voltage-clamp. We recorded nerve evoked junctional currents (nEJCs) in the different genotypes at low extracellular $\mathrm{Ca}^{2+}$, a condition where basal changes in release probability are easily distinguishable (Acharya et al., 2006; Jorquera et al., 2012; Stevens et al., 2012). Control strains carrying the neuronal GAL4 driver (elav-C155) or the UASATP7 transgene were similar in their nEJCs amplitude (Fig. $9 \mathrm{~A}$ ). However, COGI ${ }^{002840 /+}$ haploinsufficiency and ATP7 neuronal overexpression/copper efflux displayed increased nEJC amplitudes (Fig. 9A). The nEJCs were significantly larger in COG1 haploinsufficiency and ATP7 neuronal overexpression by 3 -fold and 4 -fold, respectively (Fig. 9A,B). This nEJC amplitude phenotype was rescued in $C O G 1^{02840 /+}$ animals overexpressing ATP7 in neurons (Fig. 9A,B). The phenotype of large amplitude in nEJCs in COG1 $1^{e 2840 /+}$ animals suggests an increased release probability, as synaptic size and bouton number directly correlate with the amplitude of the overall synaptic responses in healthy synapses (Zhang et al., 2001; Menon et al., 2013). However, in pathologic conditions, diverse homeostatic mechanisms of compensation can modify the release probability (Wondolowski and Dickman, 2013; Davis and Müller, 2015; Frank et al., 2020), evident in ATP7A overexpressing neurons, where the amplitude inversely correlates with the synaptic growth phenotype (Figs. 3C,D, 9A,B).

A synaptic response can be prolonged with increases in release probability, therefore we looked at the nEJCs kinetics. Normalizing average responses during nerve stimulation at

low-frequency (Fig. 9C) and estimating a skew values index of kurtosis dividing the charge transferred by their peak amplitude (Fig. 9D), show the slower timing in COG1-haploinsufficiency and ATP7 neuronal overexpression by 2.5 and $2 \mathrm{~ms}$, respectively. This phenotype is rescued partially in animals carrying COG1 $1^{\text {eO2840/ }}$

and expressing the UAS-ATP7 transgene in neurons, indicating that the ATP7 levels modulate amplitude and kinetics of synaptic responses. The neurotransmission phenotype in $C O G 1^{e 02840 /+}$ and neuronal expressed ATP7 animals agree with increased release probability, we further tested this hypothesis measuring facilitation using paired-pulse and tetanic stimulation. To determine the facilitation index in these genotypes, we applied paired-pulse stimulation spaced by $50 \mathrm{~ms}$ (Fig. 9E,F). Control strains facilitate, COG1 $1^{e 02840 /+}$, and ATP7 neuronal overexpression facilitate similarly (Fig. 9E,F). However, tetanic facilitation after a brief train of stimuli at $20 \mathrm{~Hz}$ is decreased significantly in animals overexpressing ATP7 in neurons (Fig. 9G,H), indicating a quick saturation in the release probability during nerve activity. These phenotypes were rescued by COG1 haploinsufficiency with the COG1 $1^{\text {eO2840/+ }}$ allele (Fig. 9G,H). Altogether, our results demonstrate that ATP7 levels in motor neurons increase the overall initial release probability.

The COG complex and ATP7 modify tetanic and post-tetanic short-term synaptic plasticity

Neuronal transmission undergoes short-term changes in synaptic efficacy during high-frequency nerve activation. After the conditioning episode ceases, these changes in synaptic efficacy persist and are progressively restored to their preconditioned values over time, a phenomenon known as short-term synaptic memory. Short-term synaptic memory is key for learning and working memory, as determined in Drosophila mutants with altered Pavlovian memory retention where neuromuscular synaptic modifications correlate with memory retention phenotypes (Zhong and $\mathrm{Wu}, 1991)$. To scrutinize the effects of tetanic and post-tetanic plasticity, we analyzed the nEJCs during a protocol that induces PTP under low release probability conditions (Fig. 10). In all genotypes, test stimulation for $40 \mathrm{~s}$ at $0.5 \mathrm{~Hz}$ evoked stable nEJCs (Fig. $10 A, B)$. However, the tetanic episode, induced by $25 \mathrm{~s}$ of nerve stimulation at $20 \mathrm{~Hz}$, dramatically enhance the synaptic transmission decaying in control to the pretetanic average values within 50 $s$ of test stimulation after the conditioning episode ceased (Fig. $10 A, B)$. However, COG1 $1^{e 02840 /+}$ and neuronal overexpressed ATP7 synapses cannot sustain this increase (Fig. 10A,B). Besides, synaptic transmission decayed after a tetanic episode below the test control in both genotypes, suggesting the presence of a tetanic depression and PTD. The phenotype observed in synapses overexpressing ATP7 was rescued by the COG1 $1^{02840 /+}$ allele (Fig. 10A, $B$ ) indicating that the genetic interaction between ATP7 and the COG complex is necessary to sustain short-term plasticity.

To evaluate the presynaptic sources that could modify neurotransmission in these genotypes, we tested the capacity to change their synaptic efficacy by looking in detail at the tetanic and post- 
A

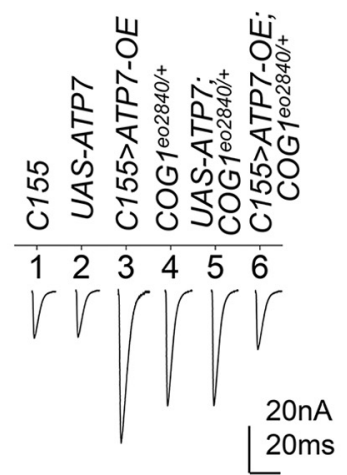

E

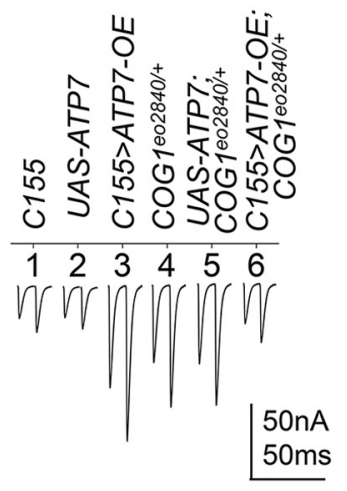

B

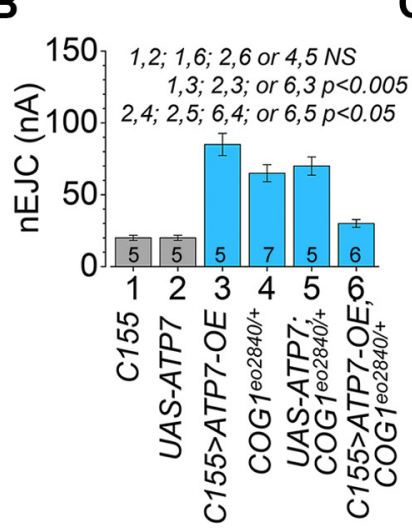

F

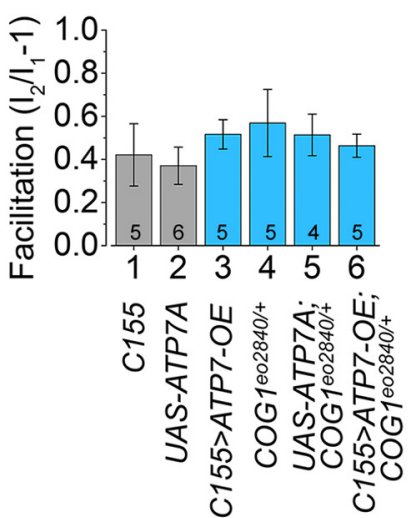

C

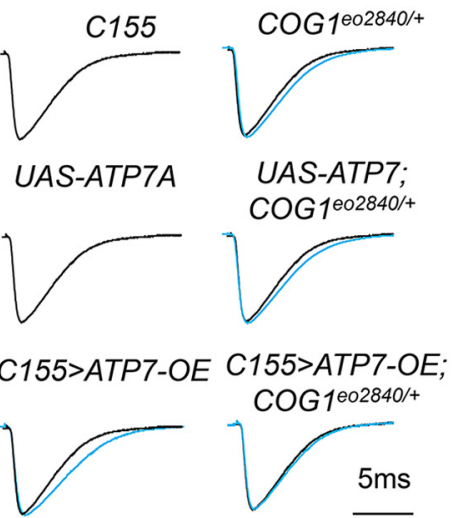

G

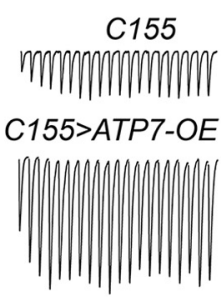

UAS-ATP7:
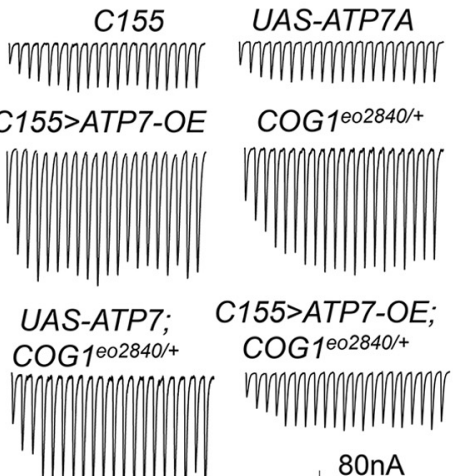

C155>ATP7-OE:
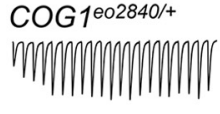

D

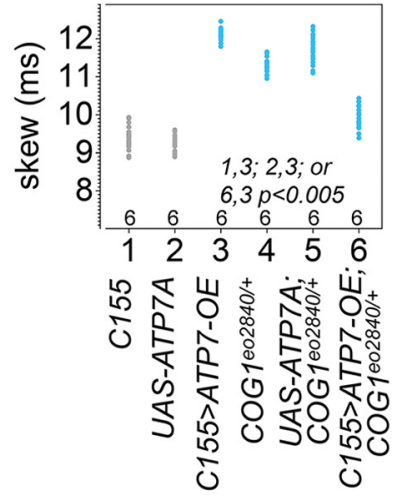

$\mathrm{H}$

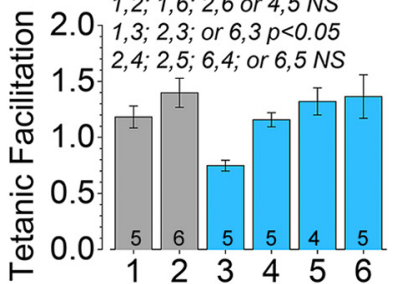

80nA

200ms

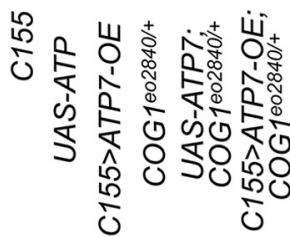

Figure 9. The COG complex and ATP7 modifies nerve-evoked synaptic transmission and fast plasticity. Representative nECS in each genotype at $0.2 \mathrm{~mm}$ extracellular $\mathrm{Ca}^{2+}(\boldsymbol{A})$ and the average amplitude $(\boldsymbol{B})$. Overlapping of the average normalized $\mathrm{nECS}$ in each genotype magnified in a new time window $(\boldsymbol{C})$ and the skew factor of kurtosis in each genotype (D). Facilitation in each genotype induced by two pulses spaced at $50 \mathrm{~ms}(\boldsymbol{E})$ and the average $(\boldsymbol{F})$. Representative recording of $\mathrm{nEC}$ (s during short-term tetanic facilitation induced with nerve stimulation at $20 \mathrm{~Hz}$ (G) and the average tetanic facilitation $(\boldsymbol{H}) ; n$ of animals per genotype are presented by the number at the base each column. One-way ANOVA followed by Tukey's HSD post hoc test.
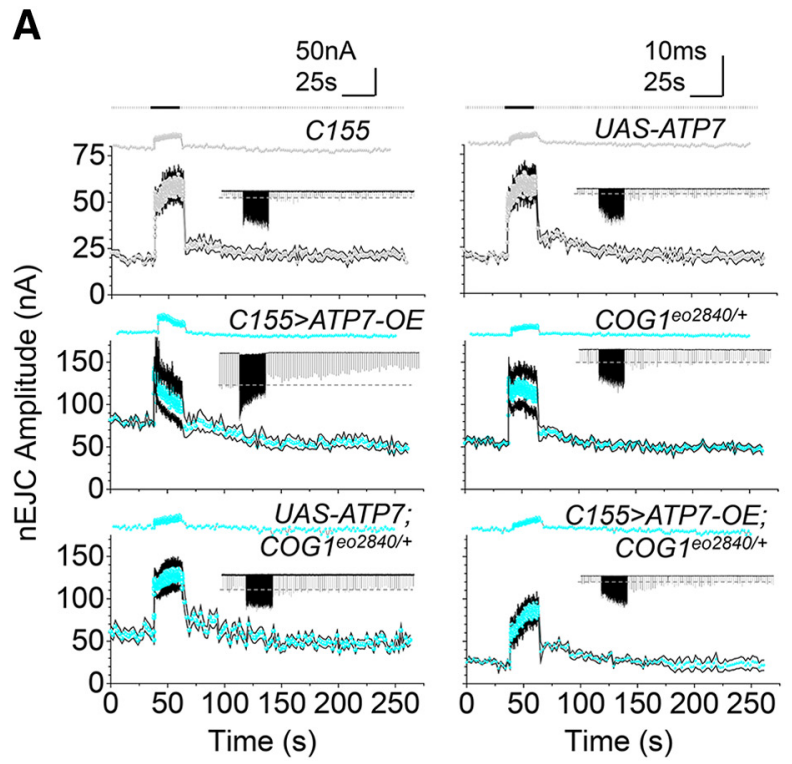

B

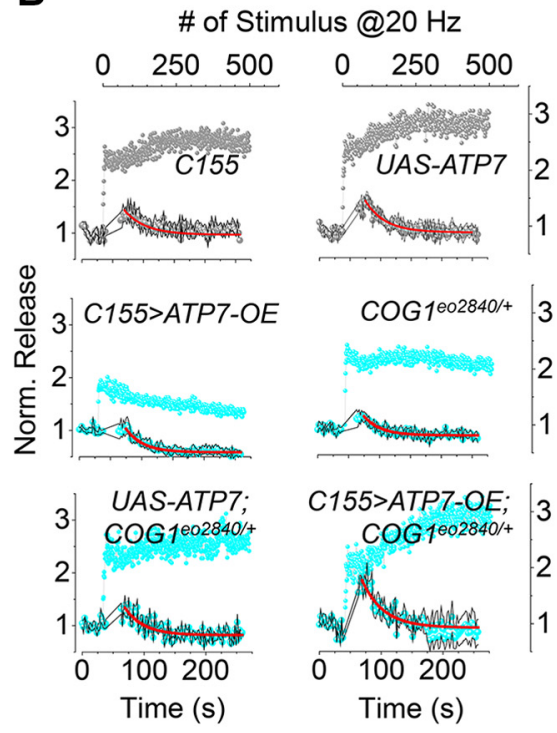

C

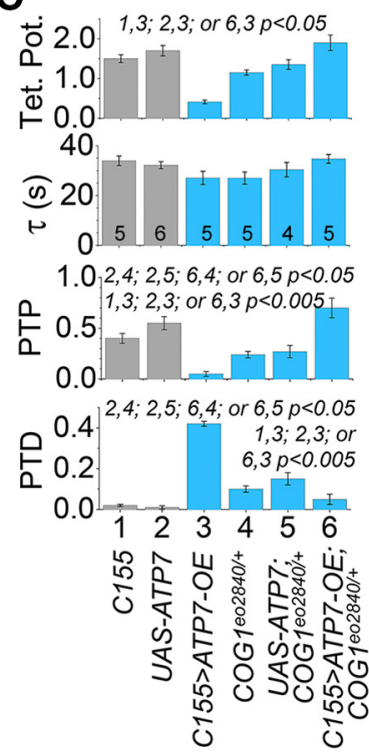

Figure 10. The COG complex and ATP7 alter short-term synaptic-plasticity in conditioning and postconditioning episodes. A, Average amplitude of nEJCs during the application of a shortterm synaptic memory protocol in each genotype, and representative electrophysiological recordings of synaptic transmission (inset). The average instantaneous skewness in each condition is displayed at the top. Test and conditioning stimulation were conducted at 0.5 and $20 \mathrm{~Hz}$, respectively. $\boldsymbol{B}$, Average responses during the low-frequency test stimulation $(0.5 \mathrm{~Hz})$ before and after the tetanic episode normalized by the pretetanic value, and the average increase in synaptic efficacy during tetanic activity in each genotype. $\boldsymbol{C}$, The average estimation for tetanic potentiation, PTP, and depression, with the time constant of transition. All graphs in $C$ have the same $n$ of animals per genotype. These are presented by the number at the base the tau columns. One-way ANOVA followed by Tukey's HSD post hoc test. 
tetanic plasticity parameters (Fig. 10C). Normalized tetanic responses indicate that all genotypes display different profiles of enhancement after the initial tetanic facilitation phase (Fig. 10B). Nerve activity induces the characteristic phase of augmentation within $10 \mathrm{~s}$ and it reaches the maximal potentiation in synaptic enhancement in control strains. Synapses from animals carrying the $C O G 1^{e 02840 /+}$ allele took less time during the augmentation phase, also reaching lower potentiation levels (Fig. 10B,C). In turn, ATP7 neuronal overexpression rapidly progressed to depression (Fig. $10 A-C$ ). These data are consistent with an increase in release probability and abnormal synaptic vesicle availability during periods of high demand. Interestingly, this synaptic behavior resembles the phenotype observed in Drosophila drp1, mutants devoid of mitochondria in presynapses (Verstreken et al., 2005). However, the synaptic transmission behavior occurring during postconditioning episodes, such as short-term synaptic memory, is undetermined in this kind of synapses (Verstreken et al., 2005). Pretetanic and posttetanic response analysis indicate that control strains induced the characteristic PTP decaying to pretetanic values with a time constant of $45 \mathrm{~s}$ (Fig. 10A-C). However, the COG1 $1^{\text {e02840/ }}$ + allele displayed less PTP which progressed to PTD (Fig. $10 A-C)$. This PTP phenotype was even more pronounced in ATP7 overexpressing neurons, which supports the concept of abnormal synaptic vesicle availability during high demand activity. Importantly, these PTP phenotypes observed in either COG $1^{e 02840 /+}$ or ATP7 overexpressing animals were rescued in animals simultaneously carrying the COG $1^{e 02840 /+}$ allele and expressing ATP7 in neurons (Fig. 10A-C). Our data demonstrate that genetic interactions between ATP7 and the COG complex, that maintain neuronal copper homeostasis, are necessary for synaptic function, including basal probability of vesicle release, synaptic vesicle availability, and short-term plasticity during conditioning and postconditioning episodes.

\section{Discussion}

We demonstrate phylogenetically conserved genetic interactions between ATP7 paralogs and a Golgi complex tether, the COG complex. Disruption of these interactions alters presynaptic function, mitochondrial content, and plasticity. Drosophila phenotypes caused by changes in the expression of ATP7 are modulated by downregulation of COG complex subunits in diverse neurons. These cell types are affected in Menkes disease by mechanisms yet to be fully explored but postulated to include defective activity of cuproenzymes in mitochondria (Zlatic et al., 2015; Hartwig et al., 2019; Guthrie et al., 2020). We conclude that genetic and biochemical interactions between ATP7 and COG are necessary to maintain cellular copper homeostasis, which in turn is necessary for mitochondria functional integrity and localization.

The steady state expression of ATP7A, CTR1, and COG complex subunits requires the mutual integrity of these genes to maintain their balanced expression. The ablation of the COG complex downregulates these copper transporters in mammalian cells in a cell-autonomous manner (Comstra et al., 2017). This observation led us to design a set of genetic tests of copper homeostasis predictions in Drosophila tissues (Fig. 2A). We scrutinized these copper homeostasis predictions using both systemic and cell-autonomous changes in the expression of ATP7, CTR1, and COG complex subunits (Fig. 2A). We used ATP7 neuronal cellautonomous overexpression to induce cytoplasmic copper efflux from cells, thus mimicking one of the Menkes-like states which are characterized by both reduced cytoplasmic and Golgi copper (Fig. 2A4). Conversely, ATP7 RNAi was used to increase cellular copper (Fig. 2A6). These are established paradigms to study copper homeostasis in Drosophila (Norgate et al., 2006; Burke et al., 2008; Hwang et al., 2014; Mercer et al., 2016). We conclude that ATP7-dependent and CTR1-dependent copper homeostasis is under control of the COG complex in neurons. The following genetic evidence supports this assertion: (1) the rescue of diverse developmental neuronal cell-autonomous ATP7 overexpression/ copper efflux phenotypes in neuronal tissues by COG gene defects (Figs. 3C, 4A, 6-10); (2) the COG-dependent rescue of cell-autonomous ATP7 RNAi/copper accumulation phenotypes in neurons which we propose represents a reduced CTR transport activity at the plasma membrane (Figs. $3 E, 5 B$ ); (3) the rescue of copper induced mortality phenotype by cell-autonomous downregulation of three COG complex subunits in aminergic neurons (Fig. 5B); (4) the rescue of a synaptic haploinsufficiency COG phenotype by systemic overexpression of ATP7 (Fig. 2A); (5) the similar rescue of cell-autonomous ATP7 RNAi/copper accumulation synaptic phenotypes granted by either neuronalspecific COG subunit or CTR1 downregulation (Fig. 2E); and (6) finally, the rescue of mitochondrial respiration defects by copper ionophores in COG-null human cells (Fig. 6).

While our genetic and biochemical analyses point to a contribution of copper in COG deficient phenotypes in flies and mammalian cells, it is reasonable to expect the contribution of other receptors and membrane transporter to neuronal phenotypes described here. COG genetic defects characteristically impair the activity of glycosyltransferases localized to the Golgi complex (Ungar et al., 2002; Zolov and Lupashin, 2005; Climer et al., 2015; Bailey Blackburn et al., 2016; Blackburn et al., 2018; D'Souza et al., 2019). These enzymes are no longer retained in the Golgi apparatus of COG-deficient cells, leading to a global decrease in the glycosylation of proteins traversing the secretory pathway. This defective glycosylation destabilizes membrane proteins residing in the endomembrane system in mammals and Drosophila (Ungar et al., 2002; Zolov and Lupashin, 2005; Shestakova et al., 2006; Pokrovskaya et al., 2011; Climer et al., 2015; Bailey Blackburn et al., 2016; Frappaolo et al., 2017). These COG-dependent biochemical defects would determine phenotypes in human COG mutations, also known as congenital disorders of glycosylation Type II. However, which neuronal proteins undergo defective glycosylation and destabilizations in this disorder is still unclear (Barone et al., 2014; Climer et al., 2015, 2018). We speculate that neurotrophic factors and receptors, synaptic adhesion molecules, calcium and ion channels, and/or synaptic membrane proteins may contribute to the synaptic phenotypes observed in COG deficient Drosophila neurons (Kadmon et al., 1990; Han et al., 2004; Kleene and Schachner, 2004; Dong et al., 2008; Kwon and Chapman, 2012; Weiss et al., 2013; Lazniewska and Weiss, 2017).

A prominent phenotype observed in neurons where copper efflux is increased by ATP7 overexpression (Fig. 2A4), and a focus of our studies, is a depletion of mitochondria at neuromuscular synapses and dendrites. This mitochondrial phenotype is concomitant with an accumulation of mitochondria in the ventral nerve cord where motor neuron cell bodies reside (Fig. $7 A, E)$. These Drosophila mitochondrial phenotypes are reminiscent of mitochondrial defects in Menkes disease (Yoshimura and Kudo, 1983; Onaga et al., 1987; Yamano et al., 1988; Zlatic et al., 2015). We attribute the mitochondrial phenotype in ATP7 overexpressing neurons to defective copper loading in mitochondria, yet this idea needs a direct experimental test as the one 
performed in a mouse Menkes model (Guthrie et al., 2020). Our observation that COG-null human cells are defective in cellular copper and mitochondrial respiration, the later rescued by copper ionophores, support a model of copper depletion-dependent damage of mitochondria (Fig. 6). Irrespective of whether mitochondria are impaired solely by copper-dependent mechanisms or other additional mechanisms that require copper transporter activity, such as oxidative stress; we postulate that functional mitochondria defects may either prevent their delivery to nerve terminals by impairing mitochondria attachment to kinesin motors, prevent their anchoring to nerve terminals, and/or induce their engulfment by mitophagy, thus trapping them in cell bodies. Copper-dependent damage of mitochondria alters their morphology, uncouples the respiratory chain depolarizing mitochondria, and induces mitophagy (Yoshimura and Kudo, 1983; Yamano and Suzuki, 1985; Onaga et al., 1987; Yamano et al., 1988; Gu et al., 2000; Zischka et al., 2011; Bhattacharjee et al., 2016; Lichtmannegger et al., 2016; Polishchuk et al., 2019). Mitochondrial uncoupling and depolarization change mitochondria kinesin-dependent movement and induce mitophagy in cell bodies (Overly et al., 1996; Miller and Sheetz, 2004; Roberts et al., 2008; Verburg and Hollenbeck, 2008; Wang et al., 2011; Cai et al., 2012; Sheng and Cai, 2012; Ashrafi et al., 2014; Mishra and Chan, 2016; Misgeld and Schwarz, 2017). This evidence suggests that these mitochondrial distribution mechanisms may be perturbed or engaged in neurons whose copper homeostasis is disrupted by defects in ATP7 and/or the COG complex.

Synapse morphology, mitochondrial content, evoked neurotransmission, and short-term plasticity are modified by changes in the expression of ATP7 and COG complex subunits (Figs. 3$4,7-10)$. How these phenotypes are intertwined into cause and effect relationships remains to be explored. We speculate, however, that the absence of mitochondria may account in part for the modified neurotransmission observed in ATP7 overexpression/copper efflux synapses. Mitochondria could contribute to synapses: their calcium buffering capacity (Vos et al., 2010), their ATP synthase activity (Rangaraju et al., 2014), their Krebs cycle metabolites capable of modulating neurotransmission (Ugur et al., 2017), or enzymatic activities necessary for glutamate metabolism (Kovacevic and McGivan, 1983). In addition, mitochondria could offer metabolic flexibility diversifying sources of carbon entering the Krebs cycle for energy production at the synapse (pyruvate, glutamate, or fatty acids; Olson et al., 2016). As an example, synaptic calcium regulation by mitochondria may explain some of the neurotransmission phenotypes in ATP7 overexpression/copper efflux brains. Short episodes of high-frequency nerve-stimulation induce plasticity in the form of facilitation, augmentation, and potentiation. These are all shortterm increases in the efficacy of synaptic transmission, also known as synaptic enhancement (Zucker and Regehr, 2002). Facilitation depends on the residual $\mathrm{Ca}^{2+}$ after influx; in turn, augmentation relies on the management of the resting $\mathrm{Ca}^{2+}$ during nerve activity, which promotes the exocytosis of the readily releasable pool of vesicles, whereas potentiation depends mostly on the exo/endocytic balance (Zucker et al., 1991; Kamiya and Zucker, 1994; Regehr et al., 1994). Post-tetanic facilitation and augmentation phenomena are related to the decay of residual calcium (Edelman et al., 1987; Zucker et al., 1991; Zucker and Regehr, 2002). However, the resting calcium explains the PTP, indicating that during activity the rising calcium drives phosphorylation-dependent signaling activation, which lasts longer than the calcium transient itself (Macleod et al., 2002; Lnenicka et al., 2006). In that sense, mitochondria could be recruited during the development of PTP (Tang and Zucker, 1997; Zhong et al., 2001). Thus, mitochondria could maintain or modulate calcium levels at the nerve terminal to sustain diverse forms of synaptic plasticity by buffering the tetanic activity critical for postconditioning episodes like shortterm synaptic memory. Our data show that tetanic and post-tetanic synaptic enhancements are altered in ATP7 overexpressing/copper efflux synapses, a phenotype that can be reverted by COG complex downregulation. We do not have direct evidence that mitochondria are solely responsible for the synaptic phenotypes in ATP7 overexpression. However, the parallel rescue of both mitochondrial content and neurotransmission phenotypes in ATP7 overexpression synapses after COG complex downregulation strongly support the hypothesis of a mitochondrialdependent mechanisms account for the neurotransmission phenotypes in these terminals. We propose that copper dyshomeostasis synaptic phenotypes in the fly provide a foundation to understand behavioral and neurologic phenotypes characteristic of Menkes and Wilson disease.

\section{References}

Acharya U, Edwards MB, Jorquera RA, Silva $H$, Nagashima K, Labarca $P$, Acharya JK (2006) Drosophila melanogaster Scramblases modulate synaptic transmission. J Cell Biol 173:69-82.

Allensworth JL, Evans MK, Bertucci F, Aldrich AJ, Festa RA, Finetti P, Ueno NT, Safi R, McDonnell DP, Thiele DJ, Van Laere S, Devi GR (2015) Disulfiram (DSF) acts as a copper ionophore to induce copper-dependent oxidative stress and mediate anti-tumor efficacy in inflammatory breast cancer. Mol Oncol 9:1155-1168.

Ashrafi G, Schlehe JS, LaVoie MJ, Schwarz TL (2014) Mitophagy of damaged mitochondria occurs locally in distal neuronal axons and requires PINK1 and Parkin. J Cell Biol 206:655-670.

Astorga C, Jorquera RA, Ramírez M, Kohler A, López E, Delgado R, Córdova A, Olguín P, Sierralta J (2016) Presynaptic DLG regulates synaptic function through the localization of voltage-activated $\mathrm{Ca}(2+)$ channels. Sci Rep 6:32132.

Bahadorani S, Bahadorani P, Marcon E, Walker DW, Hilliker AJ (2010) A Drosophila model of Menkes disease reveals a role for DmATP7 in copper absorption and neurodevelopment. Dis Model Mech 3:84-91.

Bailey Blackburn J, Pokrovskaya I, Fisher P, Ungar D, Lupashin VV (2016) COG complex complexities: detailed characterization of a complete set of HEK293T cells lacking individual COG subunits. Front Cell Dev Biol $4: 23$

Baker ZN, Cobine PA, Leary SC (2017) The mitochondrion: a central architect of copper homeostasis. Metallomics 9:1501-1512.

Barone R, Fiumara A, Jaeken J (2014) Congenital disorders of glycosylation with emphasis on cerebellar involvement. Semin Neurol 34:357-366.

Berridge MV, Herst PM, Tan AS (2005) Tetrazolium dyes as tools in cell biology: new insights into their cellular reduction. Biotechnol Annu Rev $11: 127-152$.

Bhattacharjee A, Yang H, Duffy M, Robinson E, Conrad-Antoville A, Lu YW, Capps T, Braiterman L, Wolfgang M, Murphy MP, Yi L, Kaler SG, Lutsenko S, Ralle M (2016) The activity of Menkes disease protein ATP7A is essential for redox balance in mitochondria. J Biol Chem 291:16644-16658.

Binks T, Lye JC, Camakaris J, Burke R (2010) Tissue-specific interplay between copper uptake and efflux in Drosophila. J Biol Inorg Chem 15:621-628.

Blackburn JB, Lupashin VV (2016) Creating knockouts of conserved oligomeric Golgi complex subunits using CRISPR-mediated gene editing paired with a selection strategy based on glycosylation defects associated with impaired COG complex function. Methods Mol Biol 1496:145-161.

Blackburn JB, Kudlyk T, Pokrovskaya I, Lupashin VV (2018) More than just sugars: conserved oligomeric Golgi complex deficiency causes glycosylation-independent cellular defects. Traffic 19:463-480.

Bricker DK, Taylor EB, Schell JC, Orsak T, Boutron A, Chen YC, Cox JE, Cardon CM, Van Vranken JG, Dephoure N, Redin C, Boudina S, Gygi SP, Brivet M, Thummel CS, Rutter J (2012) A mitochondrial pyruvate 
carrier required for pyruvate uptake in yeast, Drosophila, and humans. Science 337:96-100.

Burke R, Commons E, Camakaris J (2008) Expression and localisation of the essential copper transporter DmATP7 in Drosophila neuronal and intestinal tissues. Int J Biochem Cell Biol 40:1850-1860.

Cai Q, Zakaria HM, Simone A, Sheng ZH (2012) Spatial parkin translocation and degradation of damaged mitochondria via mitophagy in live cortical neurons. Curr Biol 22:545-552.

Calvo SE, Clauser KR, Mootha VK (2016) MitoCarta2.0: an updated inventory of mammalian mitochondrial proteins. Nucleic acids Res 44:D12511257.

Camakaris J, Danks DM, Ackland L, Cartwright E, Borger P, Cotton RG (1980) Altered copper metabolism in cultured cells from human Menkes' syndrome and mottled mouse mutants. Biochem Genet 18:117-131.

Clark NL, Alani E, Aquadro CF (2012) Evolutionary rate covariation reveals shared functionality and coexpression of genes. Genome Res 22:714-720.

Clark NL, Alani E, Aquadro CF (2013) Evolutionary rate covariation in meiotic proteins results from fluctuating evolutionary pressure in yeasts and mammals. Genetics 193:529-538.

Climer LK, Dobretsov M, Lupashin V (2015) Defects in the COG complex and COG-related trafficking regulators affect neuronal Golgi function. Front Neurosci 9:405.

Climer LK, Hendrix RD, Lupashin VV (2018) Conserved oligomeric Golgi and neuronal vesicular trafficking. Handb Exp Pharmacol 245:227-247.

Comstra HS, McArthy J, Rudin-Rush S, Hartwig C, Gokhale A, Zlatic SA, Blackburn JB, Werner E, Petris M, D'Souza P, Panuwet P, Barr DB, Lupashin V, Vrailas-Mortimer A, Faundez V (2017) The interactome of the copper transporter ATP7A belongs to a network of neurodevelopmental and neurodegeneration factors. Elife 6:e24722.

Das R, Bhattacharjee S, Patel AA, Harris JM, Bhattacharya S, Letcher JM, Clark SG, Nanda S, Iyer EPR, Ascoli GA, Cox DN (2017) Dendritic cytoskeletal architecture is modulated by combinatorial transcriptional regulation in Drosophila melanogaster. Genetics 207:1401-1421.

Davis GW, Müller M (2015) Homeostatic control of presynaptic neurotransmitter release. Annu Rev Physiol 77:251-270.

Detmer SA, Chan DC (2007) Functions and dysfunctions of mitochondrial dynamics. Nat Rev Mol Cell Biol 8:870-879.

Divakaruni AS, Paradyse A, Ferrick DA, Murphy AN, Jastroch M (2014) Analysis and interpretation of microplate-based oxygen consumption and $\mathrm{pH}$ data. Methods Enzymol 547:309-354.

Dong M, Liu H, Tepp WH, Johnson EA, Janz R, Chapman ER (2008) Glycosylated SV2A and SV2B mediate the entry of botulinum neurotoxin E into neurons. Mol Biol Cell 19:5226-5237.

D’Souza Z, Blackburn JB, Kudlyk T, Pokrovskaya ID, Lupashin VV (2019) Defects in COG-mediated Golgi trafficking alter endo-lysosomal system in human cells. Front Cell Dev Biol 7:118.

Edelman GM, Gall WE, Cowan WM (1987) Synaptic function (The Neurosciences Institute Publication Series), p 789. New York: Wiley.

Findlay GD, Sitnik JL, Wang W, Aquadro CF, Clark NL, Wolfner MF (2014) Evolutionary rate covariation identifies new members of a protein network required for Drosophila melanogaster female post-mating responses. PLoS Genet 10:e1004108.

Foulquier F (2009) COG defects, birth and rise! Biochim Biophys Acta 1792:896-902

Frank CA, James TD, Müller M (2020) Homeostatic control of Drosophila neuromuscular junction function. Synapse 74:e22133.

Frappaolo A, Sechi S, Kumagai T, Robinson S, Fraschini R, KarimpourGhahnavieh A, Belloni G, Piergentili R, Tiemeyer KH, Tiemeyer M, Giansanti MG (2017) COG7 deficiency in Drosophila generates multifaceted developmental, behavioral and protein glycosylation phenotypes. J Cell Sci 130:3637-3649.

Gokhale A, Vrailas-Mortimer A, Larimore J, Comstra HS, Zlatic SA, Werner E, Manvich DF, Iuvone PM, Weinshenker D, Faundez V (2015a) Neuronal copper homeostasis susceptibility by genetic defects in dysbindin, a schizophrenia susceptibility factor. Hum Mol Genet 24:5512-5523.

Gokhale A, Mullin AP, Zlatic S, Easley CA, Merritt ME, Raj N, Larimore J, Gordon DE, Peden AA, Sanyal S, Faundez V (2015b) The N-ethylmaleimide sensitive factor and dysbindin interact to modulate synaptic plasticity. J Neurosci 35:7643-7653.

Gokhale A, Hartwig C, Freeman AH, Das R, Zlatic SA, Vistein R, Burch A, Carrot G, Lewis AF, Nelms S, Dickman D, Puthenveedu M, Cox DN, Faundez V (2016) The proteome of BLOC-1 genetic defects identifies the
Arp2/3 actin polymerization complex to function downstream of the schizophrenia susceptibility factor dysbindin at the synapse. J Neurosci 36:12393-12411.

Gu M, Cooper JM, Butler P, Walker AP, Mistry PK, Dooley JS, Schapira AH (2000) Oxidative-phosphorylation defects in liver of patients with Wilson's disease. Lancet 356:469-474.

Guthrie LM, Soma S, Yuan S, Silva A, Zulkifli M, Snavely TC, Greene HF, Nunez E, Lynch B, De Ville C, Shanbhag V, Lopez FR, Acharya A, Petris MJ, Kim BE, Gohil VM, Sacchettini JC (2020) Elesclomol alleviates Menkes pathology and mortality by escorting $\mathrm{Cu}$ to cuproenzymes in mice. Science 368:620-625.

Han W, Rhee JS, Maximov A, Lao Y, Mashimo T, Rosenmund C, Südhof TC (2004) N-glycosylation is essential for vesicular targeting of synaptotagmin 1. Neuron 41:85-99.

Hartwig C, Zlatic SA, Wallin M, Vrailas-Mortimer A, Fahrni CJ, Faundez V (2019) Trafficking mechanisms of P-type ATPase copper transporters. Curr Opin Cell Biol 59:24-33.

Ho J, Tumkaya T, Aryal S, Choi H, Claridge-Chang A (2019) Moving beyond p values: data analysis with estimation graphics. Nat Methods 16:565566 .

Horn D, Barrientos A (2008) Mitochondrial copper metabolism and delivery to cytochrome c oxidase. IUBMB Life 60:421-429.

Hwang JE, de Bruyne M, Warr CG, Burke R (2014) Copper overload and deficiency both adversely affect the central nervous system of Drosophila. Metallomics 6:2223-2229.

Iyer EP, Iyer SC, Sullivan L, Wang D, Meduri R, Graybeal LL, Cox DN (2013a) Functional genomic analyses of two morphologically distinct classes of Drosophila sensory neurons: post-mitotic roles of transcription factors in dendritic patterning. PLoS One 8:e72434.

Iyer SC, Ramachandran Iyer EP, Meduri R, Rubaharan M, Kuntimaddi A, Karamsetty M, Cox DN (2013b) Cut, via CrebA, transcriptionally regulates the COPII secretory pathway to direct dendrite development in Drosophila. J Cell Sci 126:4732-4745.

Jorquera RA, Huntwork-Rodriguez S, Akbergenova Y, Cho RW, Littleton JT (2012) Complexin controls spontaneous and evoked neurotransmitter release by regulating the timing and properties of synaptotagmin activity. J Neurosci 32:18234-18245.

Kadmon G, Kowitz A, Altevogt P, Schachner M (1990) Functional cooperation between the neural adhesion molecules L1 and N-CAM is carbohydrate dependent. J Cell Biol 110:209-218.

Kaler SG (2011) ATP7A-related copper transport diseases-emerging concepts and future trends. Nat Rev Neurol 7:15-29.

Kamiya H, Zucker RS (1994) Residual Ca2+ and short-term synaptic plasticity. Nature 371:603-606.

Kleene R, Schachner M (2004) Glycans and neural cell interactions. Nat Rev Neurosci 5:195-208.

Kovacevic Z, McGivan JD (1983) Mitochondrial metabolism of glutamine and glutamate and its physiological significance. Physiol Rev 63:547-605.

Kranz C, Ng BG, Sun L, Sharma V, Eklund EA, Miura Y, Ungar D, Lupashin V, Winkel RD, Cipollo JF, Costello CE, Loh E, Hong W, Freeze HH (2007) COG8 deficiency causes new congenital disorder of glycosylation type IIh. Hum Mol Genet 16:731-741.

Kuo YM, Zhou B, Cosco D, Gitschier J (2001) The copper transporter CTR1 provides an essential function in mammalian embryonic development. Proc Natl Acad Sci USA 98:6836-6841.

Kwon SE, Chapman ER (2012) Glycosylation is dispensable for sorting of synaptotagmin 1 but is critical for targeting of SV2 and synaptophysin to recycling synaptic vesicles. J Biol Chem 287:35658-35668.

Landgraf M, Sánchez-Soriano N, Technau GM, Urban J, Prokop A (2003) Charting the Drosophila neuropile: a strategy for the standardised characterisation of genetically amenable neurites. Dev Biol 260:207-225.

Lazniewska J, Weiss N (2017) Glycosylation of voltage-gated calcium channels in health and disease. Biochim Biophys Acta Biomembr 1859:662668.

Lee CE, Singleton KS, Wallin M, Faundez V (2020) Rare genetic diseases: nature's experiments on human development. iScience 23:101123.

Li H, Chaney S, Roberts IJ, Forte M, Hirsh J (2000) Ectopic G-protein expression in dopamine and serotonin neurons blocks cocaine sensitization in Drosophila melanogaster. Curr Biol 10:211-214.

Lichtmannegger J, Leitzinger C, Wimmer R, Schmitt S, Schulz S, Kabiri Y, Eberhagen C, Rieder T, Janik D, Neff F, Straub BK, Schirmacher P, DiSpirito AA, Bandow N, Baral BS, Flatley A, Kremmer E, Denk G, 
Reiter FP, Hohenester S, et al. (2016) Methanobactin reverses acute liver failure in a rat model of Wilson disease. J Clin Invest 126:2721-2735.

Lnenicka GA, Grizzaffi J, Lee B, Rumpal N (2006) Ca2+ dynamics along identified synaptic terminals in Drosophila larvae. J Neurosci 26:1228312293.

Lutsenko S, Barnes NL, Bartee MY, Dmitriev OY (2007) Function and regulation of human copper-transporting ATPases. Physiol Rev 87:10111046.

Macleod GT, Hegström-Wojtowicz M, Charlton MP, Atwood HL (2002) Fast calcium signals in Drosophila motor neuron terminals. J Neurophysiol 88:2659-2663.

McAllum EJ, Hare DJ, Volitakis I, McLean CA, Bush AI, Finkelstein DI, Roberts BR (2020) Regional iron distribution and soluble ferroprotein profiles in the healthy human brain. Prog Neurobiol 186:101744.

Menkes JH (1988) Kinky hair disease: twenty five years later. Brain Dev 10:77-79.

Menkes JH (1999) Menkes disease and Wilson disease: two sides of the same copper coin. Part I: Menkes disease. Eur J Paediatr Neurol 3:147-158.

Menon KP, Carrillo RA, Zinn K (2013) Development and plasticity of the Drosophila larval neuromuscular junction. Wiley Interdiscip Rev Dev Biol 2:647-670.

Mercer SW, La Fontaine S, Warr CG, Burke R (2016) Reduced glutathione biosynthesis in Drosophila melanogaster causes neuronal defects linked to copper deficiency. J Neurochem 137:360-370.

Miller KE, Sheetz MP (2004) Axonal mitochondrial transport and potential are correlated. J Cell Sci 117:2791-2804.

Misgeld T, Schwarz TL (2017) Mitostasis in neurons: maintaining mitochondria in an extended cellular architecture. Neuron 96:651-666.

Mishra P, Chan DC (2016) Metabolic regulation of mitochondrial dynamics. J Cell Biol 212:379-387.

Morgan MT, Bourassa D, Harankhedkar S, McCallum AM, Zlatic SA, Calvo JS, Meloni G, Faundez V, Fahrni CJ (2019) Ratiometric two-photon microscopy reveals attomolar copper buffering in normal and Menkes mutant cells. Proc Natl Acad Sci USA 116:12167-12172.

Mullin AP, Sadanandappa MK, Ma W, Dickman DK, VijayRaghavan K, Ramaswami M, Sanyal S, Faundez V (2015) Gene dosage in the dysbindin schizophrenia susceptibility network differentially affect synaptic function and plasticity. J Neurosci 35:325-338.

Norgate M, Lee E, Southon A, Farlow A, Batterham P, Camakaris J, Burke R (2006) Essential roles in development and pigmentation for the Drosophila copper transporter DmATP7. Mol Biol Cell 17:475-484.

Oka T, Ungar D, Hughson FM, Krieger M (2004) The COG and COPI complexes interact to control the abundance of GEARs, a subset of Golgi integral membrane proteins. Mol Biol Cell 15:2423-2435.

Olson KA, Schell JC, Rutter J (2016) Pyruvate and metabolic flexibility: illuminating a path toward selective cancer therapies. Trends Biochem Sci 41:219-230.

Onaga A, Kawasaki H, Yamano T, Shimada M, Nishimura M (1987) Light and electron microscopic study on cerebellar cortex of macular mutant mouse as a model of Menkes kinky hair disease. Brain Dev 9:265-269.

Overly CC, Rieff HI, Hollenbeck PJ (1996) Organelle motility and metabolism in axons vs dendrites of cultured hippocampal neurons. J Cell Sci 109:971-980.

Petris MJ, Mercer JF, Culvenor JG, Lockhart P, Gleeson PA, Camakaris J (1996) Ligand-regulated transport of the Menkes copper P-type ATPase efflux pump from the Golgi apparatus to the plasma membrane: a novel mechanism of regulated trafficking. EMBO J 15:6084-6095.

Pokrovskaya ID, Willett R, Smith RD, Morelle W, Kudlyk T, Lupashin VV (2011) Conserved oligomeric Golgi complex specifically regulates the maintenance of Golgi glycosylation machinery. Glycobiology 21:15541569.

Polishchuk R, Lutsenko S (2013) Golgi in copper homeostasis: a view from the membrane trafficking field. Histochem Cell Biol 140:285-295.

Polishchuk EV, Concilli M, Iacobacci S, Chesi G, Pastore N, Piccolo P, Paladino S, Baldantoni D, van IJzendoorn SCD, Chan J, Chang CJ, Amoresano A, Pane F, Pucci P, Tarallo A, Parenti G, Brunetti-Pierri N, Settembre C, Ballabio A, Polishchuk RS (2014) Wilson disease protein ATP7B utilizes lysosomal exocytosis to maintain copper homeostasis. Dev Cell 29:686-700.

Polishchuk EV, Merolla A, Lichtmannegger J, Romano A, Indrieri A, Ilyechova EY, Concilli M, De Cegli R, Crispino R, Mariniello M, Petruzzelli R, Ranucci G, Iorio R, Pietrocola F, Einer C, Borchard S,
Zibert A, Schmidt HH, Di Schiavi E, Puchkova LV, et al. (2019) Activation of autophagy, observed in liver tissues from patients with Wilson disease and from ATP7B-deficient animals, protects hepatocytes from copper-induced apoptosis. Gastroenterology 156:1173-1189.e5.

Rai D, Dey S, Ray K (2018) A method for estimating relative changes in the synaptic density in Drosophila central nervous system. BMC Neurosci 19:30.

Rangaraju V, Calloway N, Ryan TA (2014) Activity-driven local ATP synthesis is required for synaptic function. Cell 156:825-835.

Regehr WG, Delaney KR, Tank DW (1994) The role of presynaptic calcium in short-term enhancement at the hippocampal mossy fiber synapse. J Neurosci 14:523-537.

Roberts EA, Robinson BH, Yang S (2008) Mitochondrial structure and function in the untreated Jackson toxic milk (tx-j) mouse, a model for Wilson disease. Mol Genet Metab 93:54-65.

Rodriguez A, Ehlenberger DB, Dickstein DL, Hof PR, Wearne SL (2008) Automated three-dimensional detection and shape classification of dendritic spines from fluorescence microscopy images. PLoS One 3:e1997.

Ruepp A, Waegele B, Lechner M, Brauner B, Dunger-Kaltenbach I, Fobo G, Frishman G, Montrone C, Mewes HW (2010) CORUM: the comprehensive resource of mammalian protein complexes-2009. Nucleic acids Res 38:D497-D501.

Sanders SJ, Sahin M, Hostyk J, Thurm A, Jacquemont S, Avillach P, Douard E, Martin CL, Modi ME, Moreno-De-Luca A, Raznahan A, Anticevic A, Dolmetsch R, Feng G, Geschwind DH, Glahn DC, Goldstein DB, Ledbetter DH, Mulle JG, Pasca SP, et al. (2019) A framework for the investigation of rare genetic disorders in neuropsychiatry. Nat Med $25: 1477-1487$

Schindelin J, Arganda-Carreras I, Frise E, Kaynig V, Longair M, Pietzsch T, Preibisch S, Rueden C, Saalfeld S, Schmid B, Tinevez JY, White DJ, Hartenstein V, Eliceiri K, Tomancak P, Cardona A (2012) Fiji: an opensource platform for biological-image analysis. Nat Methods 9:676-682.

Sheng ZH, Cai Q (2012) Mitochondrial transport in neurons: impact on synaptic homeostasis and neurodegeneration. Nat Rev Neurosci 13:77-93.

Shestakova A, Zolov S, Lupashin V (2006) COG complex-mediated recycling of Golgi glycosyltransferases is essential for normal protein glycosylation. Traffic 7:191-204.

Singhania A, Grueber WB (2014) Development of the embryonic and larval peripheral nervous system of Drosophila. Wiley Interdiscip Rev Dev Biol 3:193-210.

Sohda M, Misumi Y, Yamamoto A, Nakamura N, Ogata S, Sakisaka S, Hirose S, Ikehara Y, Oda K (2010) Interaction of Golgin-84 with the COG complex mediates the intra-Golgi retrograde transport. Traffic 11:1552-1566.

Stevens RJ, Akbergenova Y, Jorquera RA, Littleton JT (2012) Abnormal synaptic vesicle biogenesis in Drosophila synaptogyrin mutants. J Neurosci 32:18054-18067, 18067a.

Tang Y, Zucker RS (1997) Mitochondrial involvement in post-tetanic potentiation of synaptic transmission. Neuron 18:483-491.

Ugur B, Bao H, Stawarski M, Duraine LR, Zuo Z, Lin YQ, Neely GG, Macleod GT, Chapman ER, Bellen HJ (2017) The Krebs cycle enzyme isocitrate dehydrogenase $3 \mathrm{~A}$ couples mitochondrial metabolism to synaptic transmission. Cell Rep 21:3794-3806.

Ungar D, Oka T, Brittle EE, Vasile E, Lupashin VV, Chatterton JE, Heuser JE, Krieger M, Waters MG (2002) Characterization of a mammalian Golgi-localized protein complex, COG, that is required for normal Golgi morphology and function. J Cell Biol 157:405-415.

Verburg J, Hollenbeck PJ (2008) Mitochondrial membrane potential in axons increases with local nerve growth factor or semaphorin signaling. J Neurosci 28:8306-8315.

Verstreken P, Ly CV, Venken KJ, Koh TW, Zhou Y, Bellen HJ (2005) Synaptic mitochondria are critical for mobilization of reserve pool vesicles at Drosophila neuromuscular junctions. Neuron 47:365-378.

Vos M, Lauwers E, Verstreken P (2010) Synaptic mitochondria in synaptic transmission and organization of vesicle pools in health and disease. Front Synaptic Neurosci 2:139.

Wang X, Winter D, Ashrafi G, Schlehe J, Wong YL, Selkoe D, Rice S, Steen J, LaVoie MJ, Schwarz TL (2011) PINK1 and Parkin target Miro for phosphorylation and degradation to arrest mitochondrial motility. Cell 147:893-906.

Weiss N, Black SA, Bladen C, Chen L, Zamponi GW (2013) Surface expression and function of Cav3.2 T-type calcium channels are controlled by asparagine-linked glycosylation. Pflugers Arch 465:1159-1170. 
Willett R, Blackburn JB, Climer L, Pokrovskaya I, Kudlyk T, Wang W, Lupashin V (2016) COG lobe B sub-complex engages v-SNARE GS15 and functions via regulated interaction with lobe A sub-complex. Sci Rep 6:29139.

Wondolowski J, Dickman D (2013) Emerging links between homeostatic synaptic plasticity and neurological disease. Front Cell Neurosci 7:223.

Wu X, Steet RA, Bohorov O, Bakker J, Newell J, Krieger M, Spaapen L, Kornfeld S, Freeze HH (2004) Mutation of the COG complex subunit gene COG7 causes a lethal congenital disorder. Nat Med 10:518-523.

Xiao T, Ackerman CM, Carroll EC, Jia S, Hoagland A, Chan J, Thai B, Liu CS, Isacoff EY, Chang CJ (2018) Copper regulates rest-activity cycles through the locus coeruleus-norepinephrine system. Nat Chem Biol 14:655-663.

Yamano T, Suzuki K (1985) Abnormalities of Purkinje cell arborization in brindled mouse cerebellum. A Golgi study. J Neuropathol Exp Neurol 44:85-96.

Yamano T, Shimada M, Onaga A, Kawasaki H, Iwane S, Ono K, Nishimura M (1988) Electron microscopic study on brain of macular mutant mouse after copper therapy. Acta Neuropathol 76:574-580.

Yang CH, Rumpf S, Xiang Y, Gordon MD, Song W, Jan LY, Jan YN (2009) Control of the postmating behavioral switch in Drosophila females by internal sensory neurons. Neuron 61:519-526.

Yoshimura N, Kudo H (1983) Mitochondrial abnormalities in Menkes' kinky hair disease (MKHD). Electron-microscopic study of the brain from an autopsy case. Acta Neuropathol 59:295-303.

Zhang YQ, Bailey AM, Matthies HJ, Renden RB, Smith MA, Speese SD, Rubin GM, Broadie K (2001) Drosophila fragile X-related gene regulates the MAP1B homolog Futsch to control synaptic structure and function. Cell 107:591-603.

Zhong N, Beaumont V, Zucker RS (2001) Roles for mitochondrial and reverse mode $\mathrm{Na}+/ \mathrm{Ca} 2+$ exchange and the plasmalemma $\mathrm{Ca} 2+$ ATPase in post-tetanic potentiation at crayfish neuromuscular junctions. J Neurosci 21:9598-9607.

Zhong Y, Wu CF (1991) Altered synaptic plasticity in Drosophila memory mutants with a defective cyclic AMP cascade. Science 251:198-201.

Zischka H, Lichtmannegger J, Schmitt S, Jägemann N, Schulz S, Wartini D, Jennen L, Rust C, Larochette N, Galluzzi L, Chajes V, Bandow N, Gilles VS, DiSpirito AA, Esposito I, Goettlicher M, Summer KH, Kroemer G (2011) Liver mitochondrial membrane crosslinking and destruction in a rat model of Wilson disease. J Clin Invest 121:1508-1518.

Zlatic S, Comstra HS, Gokhale A, Petris MJ, Faundez V (2015) Molecular basis of neurodegeneration and neurodevelopmental defects in Menkes disease. Neurobiol Dis 81:154-161.

Zlatic SA, Vrailas-Mortimer A, Gokhale A, Carey LJ, Scott E, Burch R, McCall MM, Rudin-Rush S, Davis JB, Hartwig C, Werner E, Li L, Petris M, Faundez V (2018) Rare disease mechanisms identified by genealogical proteomics of copper homeostasis mutant pedigrees. Cell Syst 6:368-380. e6.

Zolov SN, Lupashin VV (2005) Cog3p depletion blocks vesicle-mediated Golgi retrograde trafficking in HeLa cells. J Cell Biol 168:747-759.

Zucker RS, Regehr WG (2002) Short-term synaptic plasticity. Annu Rev Physiol 64:355-405.

Zucker RS, Delaney KR, Mulkey R, Tank DW (1991) Presynaptic calcium in transmitter release and posttetanic potentiation. Ann NY Acad Sci 635:191-207. 